\title{
Evolution of Directional Preferences in the Supplementary Eye Field during Acquisition of Conditional Oculomotor Associations
}

\author{
Longtang L. Chen and Steven P. Wise \\ Laboratory of Neurophysiology, National Institute of Mental Health, Poolesville, Maryland 20837
}

\begin{abstract}
We assessed the preferred directions (PDs) of supplementary eye field (SEF) neurons during conditional visuomotor learning. Monkeys learned to select one of four saccadic eye movements in response to a foveal instruction stimulus (IS). ISs were either familiar or novel. Each familiar IS reliably evoked one saccade: $7^{\circ}$ left, right, up, or down from the central fixation point. Novel ISs initially triggered virtually random responses among those four possibilities, but the monkeys ultimately learned to select the instructed saccade. As reported previously, activity rates on novel IS trials significantly changed during learning. Some of these cells (learning-dependent) also have significant modulation on familiar IS trials, but others (learning-selective) lack such activity. Of the former, the familiar is activity can be either directionally selective or omnidirectional. For most neurons, PDs were apparent during all phases of learning, but they were
\end{abstract}

rarely constant. Only infrequently did a neuron's PD for novel ISs closely match that for familiar ISs throughout the learning process. In directional learning-dependent cells, the PD usually reoriented near the end of learning to resemble that for familiar IS trials. In omnidirectional cells, initially evident PDs dissipated with learning, even as the cell became more strongly modulated. Learning-selective cells typically began with significant PDs, but became unmodulated as learning progressed. Our findings show a pervasive lability in SEF PDs that may reflect a flexible and rapid remapping between inputs and responses within the premotor cortical network.

Key words: motor learning; frontal lobe; preferred direction; context dependency; supplementary eye field; spatial representation
Directional preferences (PDs) of cortical neurons have been extensively documented in primary motor and premotor areas (Georgopoulos et al., 1982, 1983, 1989, 1992; Schwartz et al., 1988; Kalaska et al., 1989, 1992; Caminiti et al., 1990, 1991; Lurito et al., 1991; Kalaska and Crammond, 1992; Schwartz, 1992, 1993, 1994; Smyrnis ct al., 1992; Ashe et al., 1993; di Pellegrino and Wise, 1993; Fu et al., 1993; Johnson et al., 1993; Ashe and Georgopoulos, 1994; Crammond and Kalaska, 1994), in the eye fields of the frontal cortex (Bruce and Goldberg, 1985; Schall, 1991a,b; Schall and Hanes, 1993; Hanes et al., 1995; Olson and Gettner, 1995) (see also Schlag and Schlag-Rey, 1987a,b; Schlag et al., 1992; Russo and Bruce, 1993; Tehovnik et al., 1994), in subcortical "motor" structures such as the cerebellum (Fortier et al., 1989) and basal ganglia (Hikosaka and Wurtz, 1983; Hikosaka et al., 1989; Buford and Anderson, 1993), and in other cortical areas such as prefrontal (Vaadia et al., 1986; Funahashi et al., 1990, 1991) and parietal (Kalaska et al., 1983, 1990; Georgopoulos et al., 1984; Barash et al., 1991; Gnadt et al., 1991; Ashe and Georgopoulos, 1994; Johnson et al., in press) cortex. Similar observations have been made for limb position and passively imposed movement at the spinal level (Bosco and Poppele, 1993). In thcories based on these findings, it is commonly assumed that the directional tuning function is a characteristic of each cell, one

\footnotetext{
Received Aug. 24, 1995; revised Jan. 5, 1996; accepted Jan. 9, 1996.

We thank Drs. Okihide Hikosaka and Jeffrey D. Schall for their comments on previous versions of this manuscript.

Correspondence should be addressed to Steven P. Wise, Laboratory of Neurophysiology, National Institute of Mental Health, P.O. Box 608, Poolesville, MD 20837 .

Dr. Chen's present address: Laboratory for Neural Information Processing, The Institute of Physical and Chemical Research (RIKEN), 2-1 Hirosawa, Wako-shi, Saitama 351-01, Japan.

Copyright (C) 1996 Society for Neuroscience $0270-6474 / 96 / 163067-15 \$ 05.00 / 0$
}

that does not change dramatically over time. However, PDs have been studied only in subjects performing overlearned behaviors.

The supplementary eye field (SEF) is an oculomotor cortical field that has been variously termed area $6 \mathrm{a} \beta, \mathrm{F} 7$, or dorsomedial frontal cortex (Schlag and Schlag-Rey, 1985, 1987a; Mann et al., 1988; di Pellegrino and Wise, 1991; Luppino et al., 1991; Matelli et al., 1991; Schall, 1991a; Bon and Lucchetti, 1992, 1994; Schlag et al., 1992; Russo and Bruce, 1993; Schall et al., 1993; Tehovnik and Lee, 1993; Tehovnik et al., 1994). We have demonstrated previously (Chen and Wise, 1995a,b) that cells in SEF, like those in the dorsal premotor cortex (Mitz et al., 1991; Germain and Lamarre, 1993), show significant evolution of their task-related activity modulation during the learning of new visuomotor associations. The present report addresses changes in PD during conditional oculomotor learning. If this measure represents a fixed property of a neuron and its information processing functions, then one would predict that PDs should be constant during learning and persist after they develop. Both predictions can be rejected.

\section{MATERIALS AND METHODS}

Subjects. The two adult, male rhesus monkeys (Macaca mulatta, 6-7 kg) used in the present study were the same as those used in Chen and Wise (1995a,b). The apparatus, surgical and histological methods, microstimulation methods and results, and the electromyographic methods are described in detail there. The basis for identification and localization of the SEF-intracortical microstimulation and the location of neurons with presaccadic activity modulation-is elaborated in those reports.

Behavioral paradigm. The monkeys sat in a primate chair, with heads fixed, facing a video screen that subtended $\pm 10^{\circ}$ of the visual field. Eye movements were monitored at 200 samples/sec with an infrared oculometer (Bouis Instruments) in front of the right eye. Each monkey was operantly conditioned to perform an oculomotor task that required the association of complex, foveal visual stimuli with a saccadic eye movement (Fig. 1). The trial began with the presentation of a blue $\left(0.1^{\circ}\right)$ 
Figure 1. Conditional oculomotor learning task. Schematic drawing of the video monitor and the monkey's oculomotor responses. $A$, The monkey maintained gaze at the central fixation point (not shown) for 500 (or occasionally 600 or 800 ) msec. A visual instruction stimulus was presented for 500 (rarely 600) msec, followed by $1.5-3.0 \mathrm{sec}$ delay period, while the fixation point remained on (left). At the trigger stimulus (fixation point off), the monkey made a saccade to one of the four targets and maintained fixation at the target for $600 \mathrm{msec}$ (right). $B$, The task periods and durations (arrows, top) and a schematic of horizontal eye position $(E h$, bottom $)$.

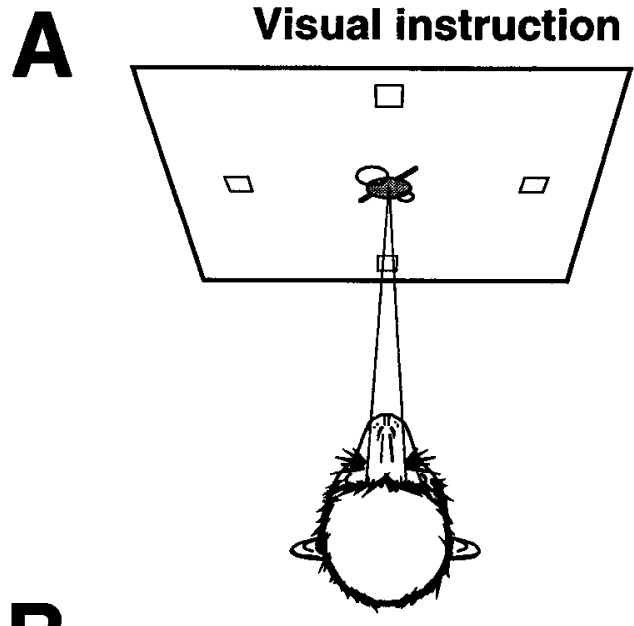

Target hold

B

\begin{tabular}{|c|c|c|c|c|}
\hline Reference & Instruction & Instructed delay & Response & Target hold \\
\hline $0.5 \mathrm{~s}$ & $0.5 \mathrm{~s}$ & $1.5-3.0 \mathrm{~s}$ & $0.55 \mathrm{~s}$ & $0.6 \mathrm{~s}$ \\
\hline
\end{tabular}

fixation spot at the center of a video screen. As soon as the monkey fixated that spot, it changed from blue to white and four potential eye-movement targets $\left(0.2^{\circ}\right.$ light green squares) simultaneously appeared: $7^{\circ}$ up, down, left, and right from center. The monkeys were required to maintain gaze angle within a $\pm 2^{\circ}$ (square) window centered on the fixation spot. As the monkeys maintained fixation, a reference period (usually $0.5 \mathrm{sec}$ ) was followed by the superimposition onto the fixation spot of a complex, visual instruction stimulus (IS) for $0.5 \mathrm{sec}$ or, occasionally, $0.6 \mathrm{sec}$ (not illustrated).

Each $\sim 2.4 \times 2.4^{\circ}$ IS was a composite of one to four elements selected from a set of rectangles and annuli of various hues, orientations, brightness levels, and sizes. Each IS instructed an eye movement to one of the four targets. Four ISs were used as familiar stimuli, one for each saccade (or target). Novel stimuli were added, usually two to four at a time, to the group of four familiar stimuli for presentation in a given block of trials. For each set of six to eight ISs, the IS on a given trial was selected pseudorandomly from the set until each had been used once. A set of ISs was used for a block of $100-300$ trials.

After IS offset, an instructed delay period of $1.5-3.0 \mathrm{sec}$ began (Fig. $1 B$ ). If the monkey failed to maintain a steady fixation during that delay period, the trial was aborted. When the delay period expired, the fixation point disappeared (Fig. $1 B$ ) as the "go," or trigger, stimulus. The monkeys then had to make a saccade to the correct $2^{\circ}$ (square) target within 0.55 $\mathrm{sec}$ and maintain gaze there for $0.6 \mathrm{sec}$ to receive reinforcement $(0.3 \mathrm{ml}$ of liquid diet). Retrials were run after incorrect responses.

Recording methods. Glass-coated, metal electrodes (1-2 M $\Omega$ measured at $1 \mathrm{kHz}$ ) were used to record neuronal activity. Single-unit potentials were filtered with a bandpass of $500 \mathrm{~Hz}$ to $6 \mathrm{KHz}$, amplified and discriminated using a Multi-Spike Detector (Alpha-Omega Engineering, Nazareth, Israel). Cells were usually isolated as the monkeys learned novel conditional oculomotor associations.

Analytical methods. We present neuronal-activity data from correctly executed trials only. Neuronal discharge during each trial was measured in five task periods (see Fig. 1): (1) a reference (baseline) period, usually $8-520 \mathrm{msec}$ before IS onset; (2) an instruction period, $80-320 \mathrm{msec}$ after IS onset; (3) part of the instructed delay period, from $400-1200 \mathrm{msec}$ before target acquisition (which did not include any time after the trigger stimulus); (4) a presaccadic period, $20-200 \mathrm{msec}$ before target acquisition; and (5) a postsaccadic, target-fixation period, from $200-600 \mathrm{msec}$ after larget acquisition. Task-related activity and the existence of significant directional biases were assessed against the reference-period activity with a two-factor ANOVA $(\alpha=0.05)$. The directional cases studied in this report were limited to those with directionality as a main effect. PDs were calculated as the circular mean angle, determined as the average of the normalized vectors for each saccade direction (Batschelet, 1981). The magnitude of directional bias corresponded to the mean vector length, which ranged from 0 to 1 . The $V$ test (Batschelet, 1981) was applied to evaluate whether the distribution of PDs had a significant asymmetry. In the present convention, $0^{\circ}$ indicates a directional bias ipsilateral to the recorded hemisphere, and $180^{\circ}$ designates a contralateral bias.

We measured activity in each task period separately. The term "case," as used in the present report, refers to the activity of a cell during a given task period. Although a neuron could, in principle, be studied in as many as four task periods, in practice, the vast majority of cells showed significant learning-related changes in only one or two task periods. Most of our analysis is based on this case-by-case analysis, which acknowledges the complexity of neural information processing in the temporal domain However, all of our findings and conclusions were confirmed in a parallel, cell-by-cell analysis. The cell-by-cell analysis was performed on neurons that exhibited excitatory modulation during either the instruction period, the presaccadic period, the instructed delay period, or both instruction and presaccadic periods, but not during any of the more complex combinations of task periods.

We separately measured activity on trials instructed by familiar ISs and those instructed by novel ones. It should be noted that novel and familiar ISs were randomly interleaved from trial to trial. As described above, stimuli were randomly selected from a set that usually included a variable number of novel ISs and the four familiar ISs.

The monkeys' performance and the evolution of neuronal activity that accompanied learning were evaluated with the change-point test (Siegel and Castellan, 1988), which detected whether the early values in a sequence of binomial or continuous variables differ from later ones. The acquisition of behavior was evaluated using the change-point test for binomial data; the changes in neuronal activity were evaluated with the change-point test for continuous variables $(\alpha=0.01)$. Reference-period activity and activity for familiar IS trials were subjected to the same time-trend analysis. All cases tested for significant time trends showed significant task-related modulation, defined as a significant difference from reference-period activity (ANOVA, $\alpha=0.05$ ).

Different phases of learning were defined on the basis of the monkey's performance, which was calculated as a centered, three-trial moving average of sequential correct and incorrect responses to an initially novel IS. The trial of criterion performance was defined for each case as the first instance of three consecutive correct responses in that moving average (see Fig. 4A,B) (Chen and Wise, 1995a). The middle trial of that group of three consecutive trials was recoded as trial number 0 . The first trial of each case was designated as the "early" phase of learning. Trials from two before until two after criterion (numbered -2 to +2 ) were designated as the "middle" phase of learning. Trials three to seven were termed the "late" phase, and last two trials were considered the "established" phase for the purpose of the present analysis. These divisions are illustrated at the bottom of Figure 4, $C$ and $D$. Note that for the middle and late phases of learning, the trials averaged to calculate a PD might arise from different periods of a learning block. By contrast, the early and estab- 

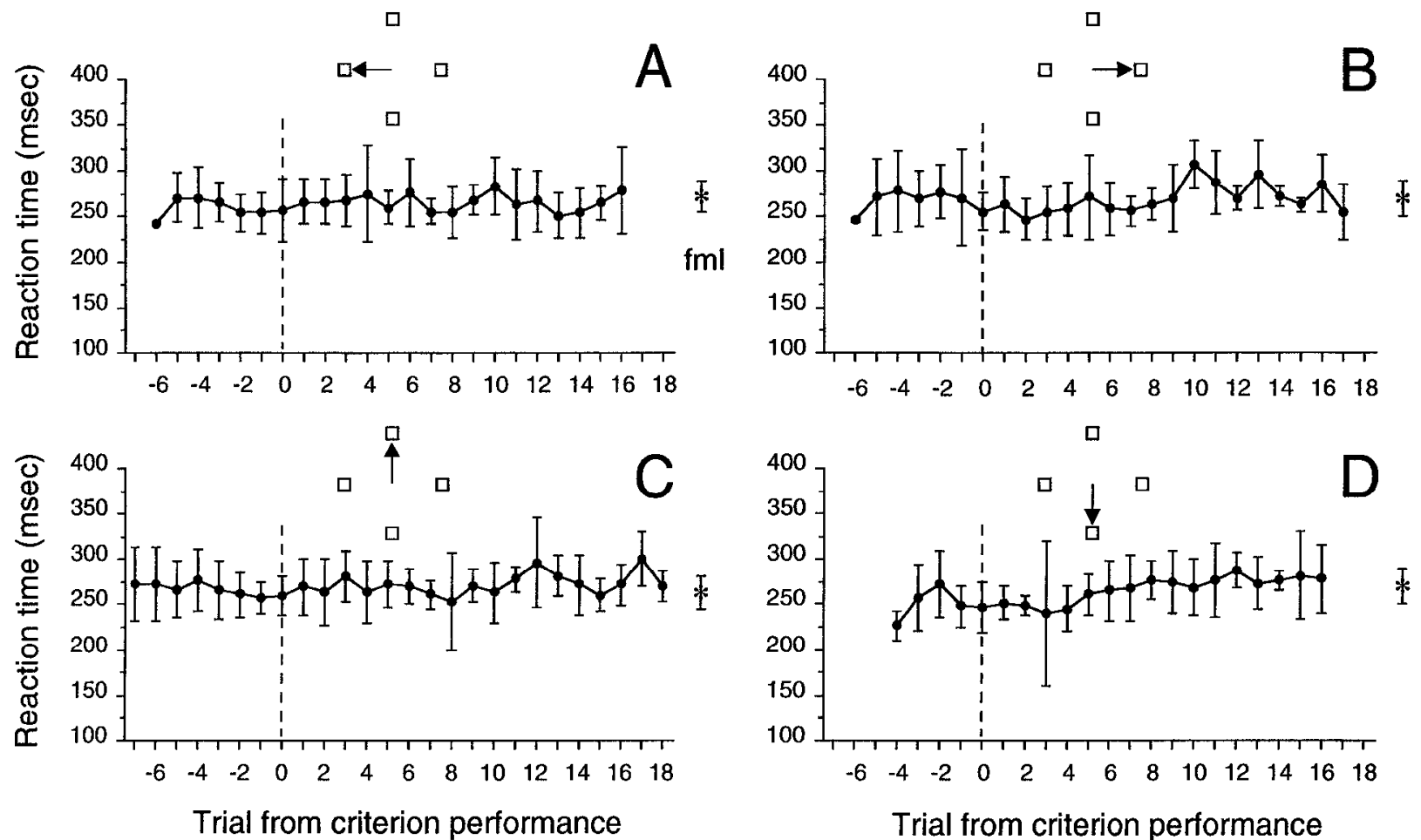

Figure 2. Mean reaction times of the second monkey for leftward $(A)$, rightward $(B)$, upward $(C)$, and downward $(D)$ saccades. Data are taken from a representative sample of behavior during 15 recording sessions, balanced over early, middle, and late data collection sessions. Correct response trials are aligned on the trial of criterion performance (trial 0 , dashed line), which is the first instance of three consecutive correct responses. Error bars indicate means \pm 1 SD. $f m l$, Familiar IS trials (asterisk).

lished phases of learning took the first or last two correctly executed trials, respectively, regardless of the animal's learning rate for the individual visuomotor associations.

To evaluate the change of PD in novel IS trials, we performed a circular statistical test on the PDs of each learning phase against the $99 \%$ confidence limit calculated from all familiar IS trials (Batschelet, 1981). Data from familiar IS trials, separated by learning phase, were subjected to the same test.

\section{RESULTS}

\section{Behavior}

The monkeys achieved $98 \%$ correct performance in response to the familiar ISs. On average, the monkeys learned the correct responses to novel ISs within approximately five correct trials, making approximately six errors in the process (Chen and Wise, 1995a). We found no significant directional biases in the monkeys' initial responses to novel ISs during learning. An analysis of the first two responses to a series of 100 novel ISs, selected only because the monkey's first response was "incorrect" and therefore unrewarded, revealed that the monkey's selections were nearly random. In terms of Tulving's (1962) "RNG" index, for which 0 indicates complete randomness and 1 shows completely ordered choices, that sample of monkey behavior yielded an RNG index of 0.18 . To put this value in perspective, most published random number tables of the early 1970's had RNG indices of $0.24 \pm 0.25$ (SD) for $n-100$, and when human subjects are asked to generate 100 random numbers they can usually do no better than 0.55 (Evans, 1978). Most of the "order" in the monkey's response stemmed from a low probability $(p=0.03)$ of repeating a previously nonreinforced response. When that factor was eliminated, the monkey's RNG index decreased to 0.06 , i.e., virtually complete randomness.

The monkeys' saccadic eye movements were highly stereotyped: they maintained stable gaze during the instructed delay period as well as during target fixation. There were no differences in eye stability for trials with familiar versus novel ISs. We found no significant difference in the response latency for the four saccade directions or during learning novel conditional oculomotor associations (Fig. 2) for either subject.

\section{Directionality of SEF cells}

About half of the SEF cases in our sample showed PDs in the task periods assessed (Chen and Wise, 1995a) (Table 1). The PDs of cases with mean circular vectors $\geq 0.2$ were analyzed further to assess their hemifield biases. There was a significant bias contraversive to the recorded hemisphere. For the instruction period, the mean angle of all PDs was $204^{\circ}(n=41$, V test; $u=1.70 ; p<$ $0.05)$; for the instructed delay period it was $159^{\circ}(n=58 ; u=1.91$; $p<0.05$ ), and for the presaccadic period the mean angle was $151^{\circ}$ ( $n=73 ; u=2.06 ; p<0.02$ ). Notwithstanding the significant contralateral biases that existed in the population, all quadrants were represented in both hemispheres.

To compare PDs in different task periods for the $34 \%$ of our neuronal sample that showed significant and directionally biased modulation in more than one task period, we calculated the circular correlation (Batschelet, 1981) as well as the mean angular difference across task periods. There was a wcak but significant negative correlation between the PDs of the instruction period and those of the instructed delay period $\left(r^{2}=0.38 ; \mathrm{df}=15 ; p<\right.$ 0.01 ) as well as a weak positive correlation between the PDs of the instructed delay period and that of the presaccadic period $\left(r^{2}=\right.$ $0.37 ; \mathrm{df}=31 ; p<0.01)$. The averaged angular difference in the former was $65 \pm 15^{\circ}$ (mean $\pm \mathrm{SE}$ ), whereas that in the latter was $37 \pm 7^{\circ}$. There was no significant correlation between the PDs of the instruction period and that of the presaccadic period $\left(r^{2}=\right.$ 
Table 1. Numbers of cases and cells by learning phase

\begin{tabular}{|c|c|c|c|c|c|c|c|c|c|}
\hline \multirow[b]{3}{*}{ Directionality for novel ISs } & \multirow[b]{3}{*}{ Task period } & \multicolumn{8}{|c|}{ Learning phase } \\
\hline & & \multicolumn{2}{|c|}{ Early } & \multicolumn{2}{|c|}{ Middle } & \multicolumn{2}{|l|}{ Late } & \multicolumn{2}{|c|}{ Established } \\
\hline & & $\begin{array}{l}\text { Fml } \\
+\end{array}$ & $\begin{array}{c}\text { Fml } \\
-\end{array}$ & $\begin{array}{l}\text { Fml } \\
+\end{array}$ & $\begin{array}{l}\text { Fml } \\
- \\
\end{array}$ & $\begin{array}{l}\text { Fml } \\
+\end{array}$ & $\begin{array}{l}\text { Fml } \\
- \\
\end{array}$ & $\begin{array}{l}\text { Fml } \\
+ \\
\end{array}$ & $\begin{array}{l}\text { Fml } \\
- \\
\end{array}$ \\
\hline \multirow[t]{6}{*}{ Directionally biased } & Instruction & 4 & 8 & 4 & 6 & 4 & 3 & 4 & 3 \\
\hline & Delay & 5 & 7 & 5 & 5 & 4 & 5 & 5 & 4 \\
\hline & Presaccade & 5 & 3 & 6 & 1 & 6 & 2 & 6 & 2 \\
\hline & Postsaccade & 5 & 3 & 5 & 4 & 5 & 3 & 4 & 3 \\
\hline & Total cases & 19 & 21 & 20 & 16 & 19 & 13 & 19 & 12 \\
\hline & Total cells & 13 & 17 & 12 & 12 & 11 & 12 & 12 & 9 \\
\hline \multirow[t]{6}{*}{ Directionally unbiased } & Instruction & 0 & 5 & 0 & 7 & 0 & 10 & 0 & 10 \\
\hline & Delay & 1 & 3 & 1 & 5 & 2 & 5 & 1 & 6 \\
\hline & Presaccade & 1 & 0 & 0 & 2 & 0 & 1 & 0 & 1 \\
\hline & Postsaccade & 1 & 7 & 1 & 6 & 1 & 7 & 2 & 7 \\
\hline & Total cases & 3 & 15 & 2 & 20 & 3 & 23 & 3 & 24 \\
\hline & Total cells & 2 & 13 & 2 & 17 & 3 & 15 & 3 & 19 \\
\hline
\end{tabular}

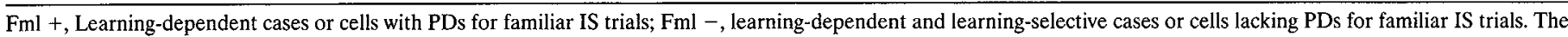
cutoff criterion for directional bias was a mean $\geq 0.2$ and activity $>3$ impulses/sec.

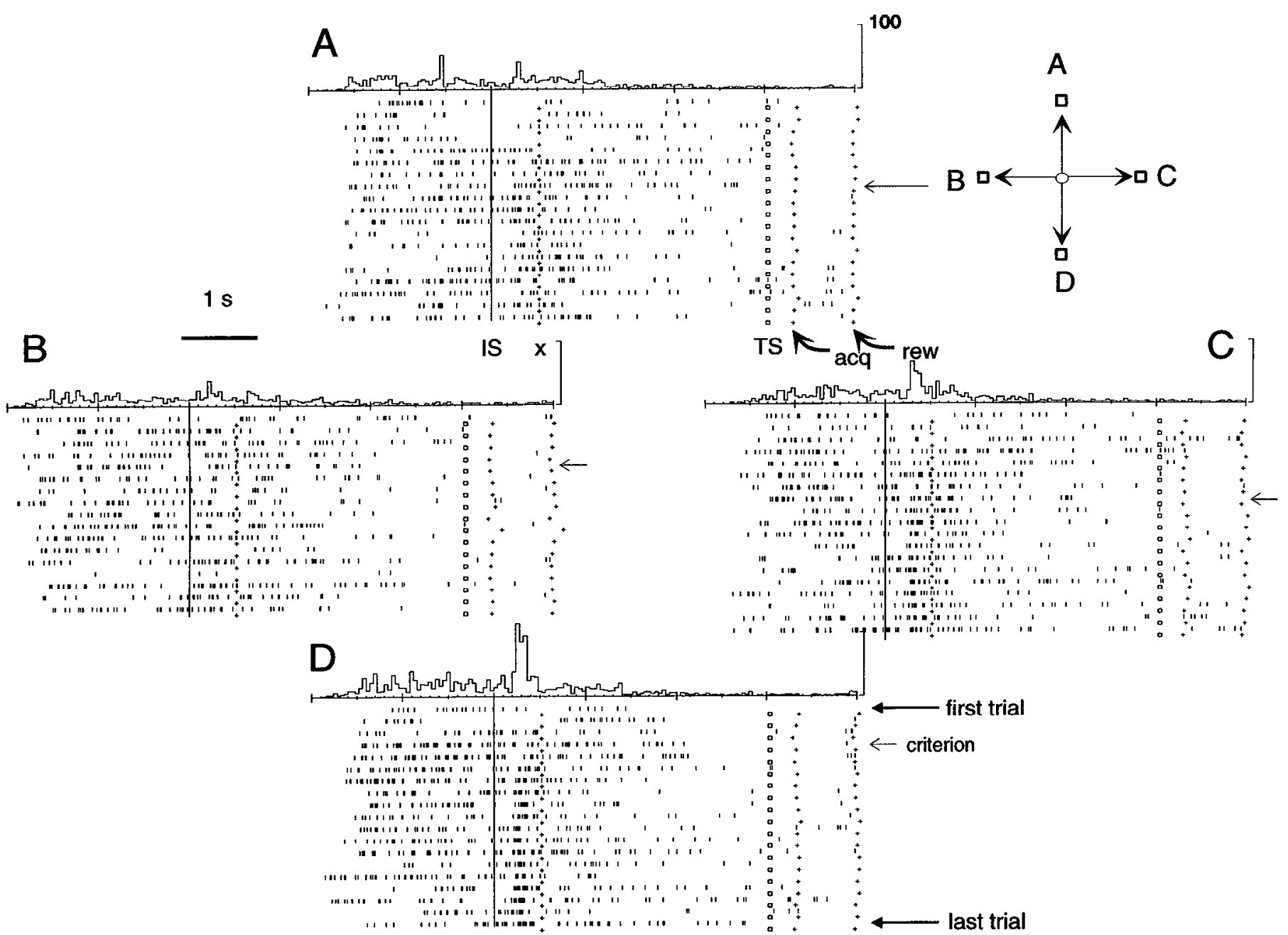

Figure 3. SEF cell with learning-dependent activity in the instruction period. $A-D$, Histogram and rasters showing the activity evolution when four saccade directions were instructed by four different novel ISs. Only data from correctly executed trials are shown, in the order of their occurrence (for each movement direction) from top (first) to bottom (last). Thin arrows mark the trial on which criterion performance was achieved (criterion). IS, Instruction stimulus onset; $x$, IS offset; TS, trigger stimulus; $a c q$, target acquisition; rew, reward. Note that the familiar IS trials and these novel ISs were interleaved pseudorandomly in the block with several other novel and familiar ISs. Activity scale in impulses/sec, the same for all plots. 

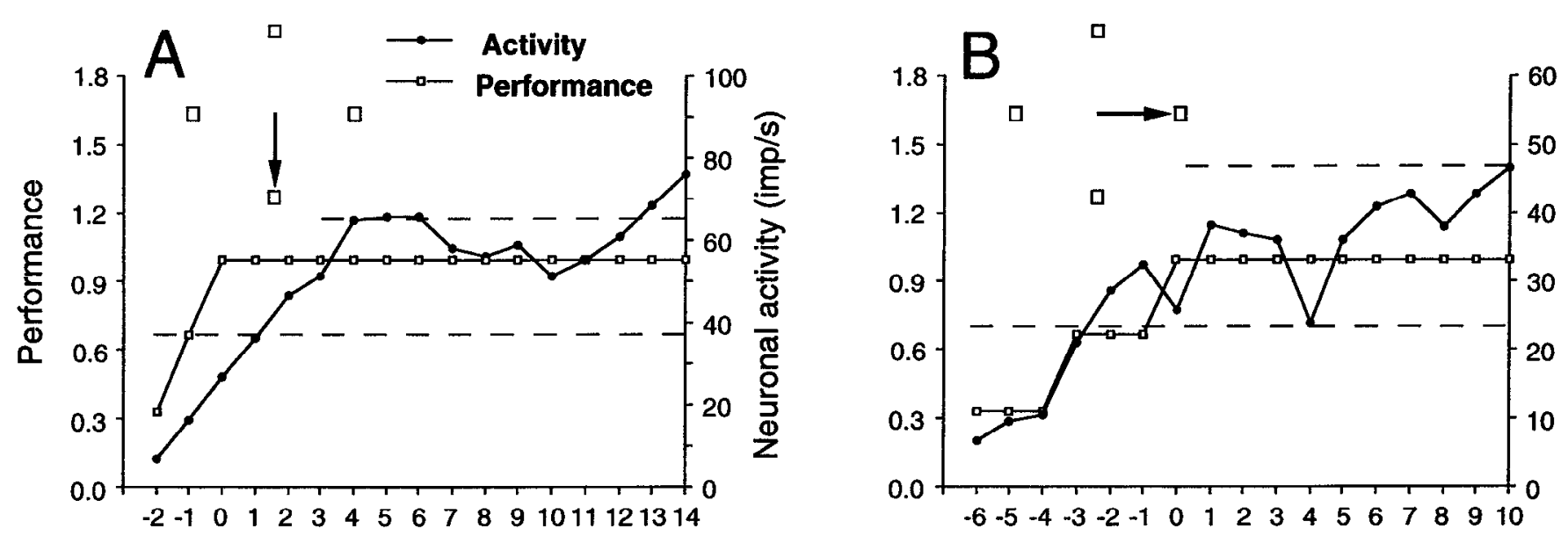

Trial from criterion performance
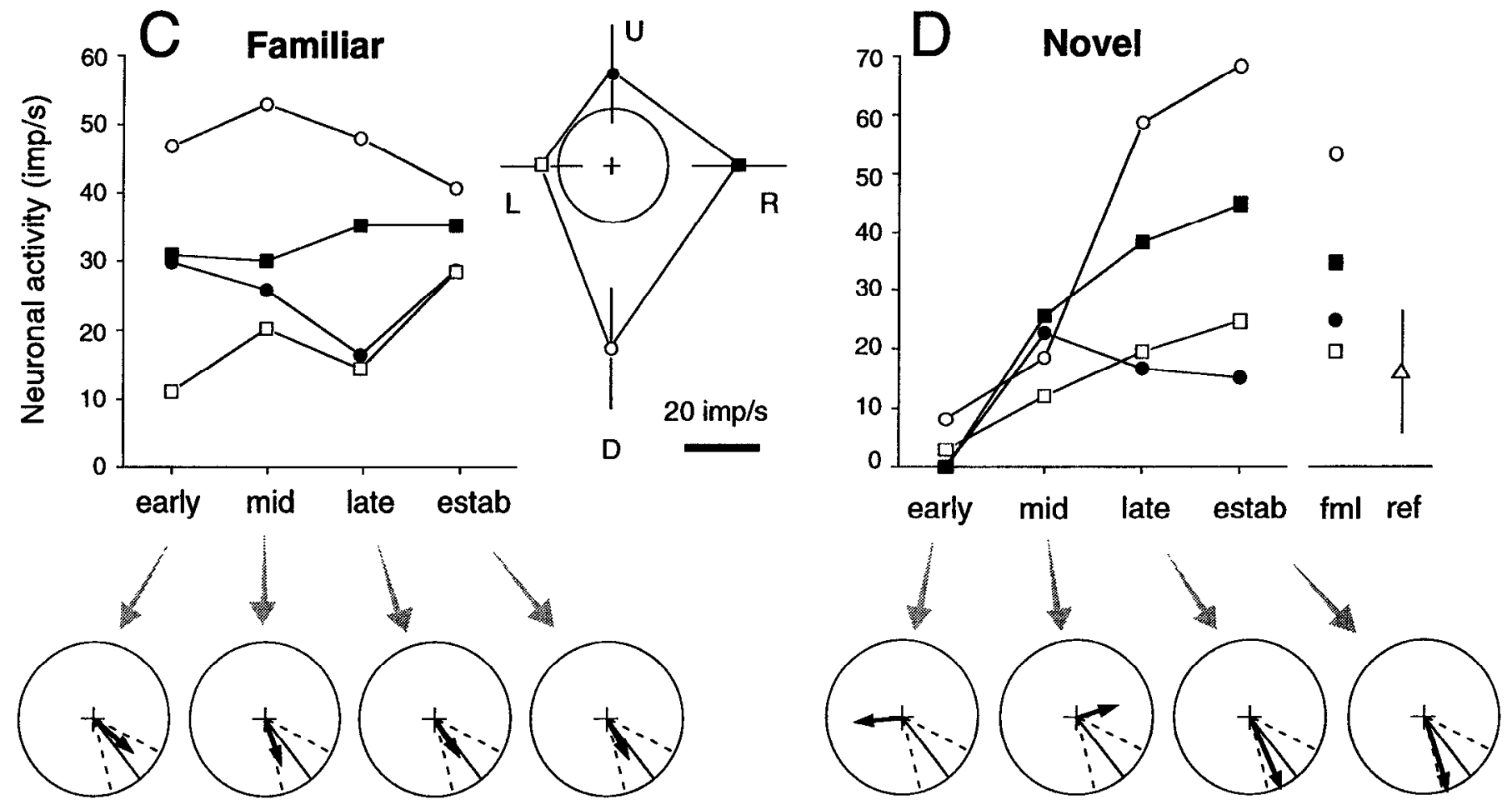

Figure 4. A, B, Three-point moving average of performance (open squares) and activity (filled circles) plotted for novel IS trials, separated for the downward $(A)$ and rightward $(B)$ saccades. From the same cell as Figure 3. Dashed horizontal lines indicate \pm 1 SD of the mean activity for the familiar IS trials. The criterion performance trial is marked as trial $0 . C$, Activity for familiar IS trials during different learning phases, and a polar plot (right) showing the mean activity and \pm 1 SD for each saccade direction. In the polar plot, the circle represents the average activity during the reference period. $D$, Activity modulation for different saccade directions and the novel ISs associated with those saccades for each phase of learning. At the bottom of $C$ and $D$, the mean vector for each learning phase is shown (bold arrow), as well as the familiar IS mean (solid radius) and $99 \%$ confidence limit (dashed radius) for the entire block. The vector length is scaled with reference to that of the novel PD during the established phase. Open circles, Down; filled squares, right; open squares, left; filled circles, up. Each value represents the average activity in a given learning phase. fml, Mean activity on familiar IS trials; ref, mean activity \pm 1 SD in reference period.

$0.15 ; \mathrm{df}=14 ; p>0.10$ ), for which the average angular difference was $62 \pm 14^{\circ}$.

\section{Directionally specific activity changes during learning}

Figure 3 illustrates the trial-by-trial evolution of neuronal activity of an SEF cell during conditional oculomotor learning. The figure shows data only for correctly performed trials, in the order (from top to bottom for each saccade direction) that they occurred. The significant task-related activity of this cell was confined to the instruction period, the time between IS onset and offset. During the first several trials of learning, i.e., the first correctly executed responses to presentations of an initially novel IS, the cell's activity was relatively unmodulated. In those early presentations, the cell showed neither task-related activity nor directional preference (Fig. $3 A-D$ ). As the monkey's performance in response to initially novel ISs improved, the activity modulation rose for the novel stimulus instructing downward saccades (Figs. $3 D$ and $4 A$ ) and, to a lesser extent, also for the stimulus instructing rightward saccades (Figs. $3 C$ and $4 B$ ). The activity gradually incremented to within an SD of the levels observed for familiar IS trials (Fig. $4 A, B$ ). 


\section{Learning Dependent- Directional Cells}
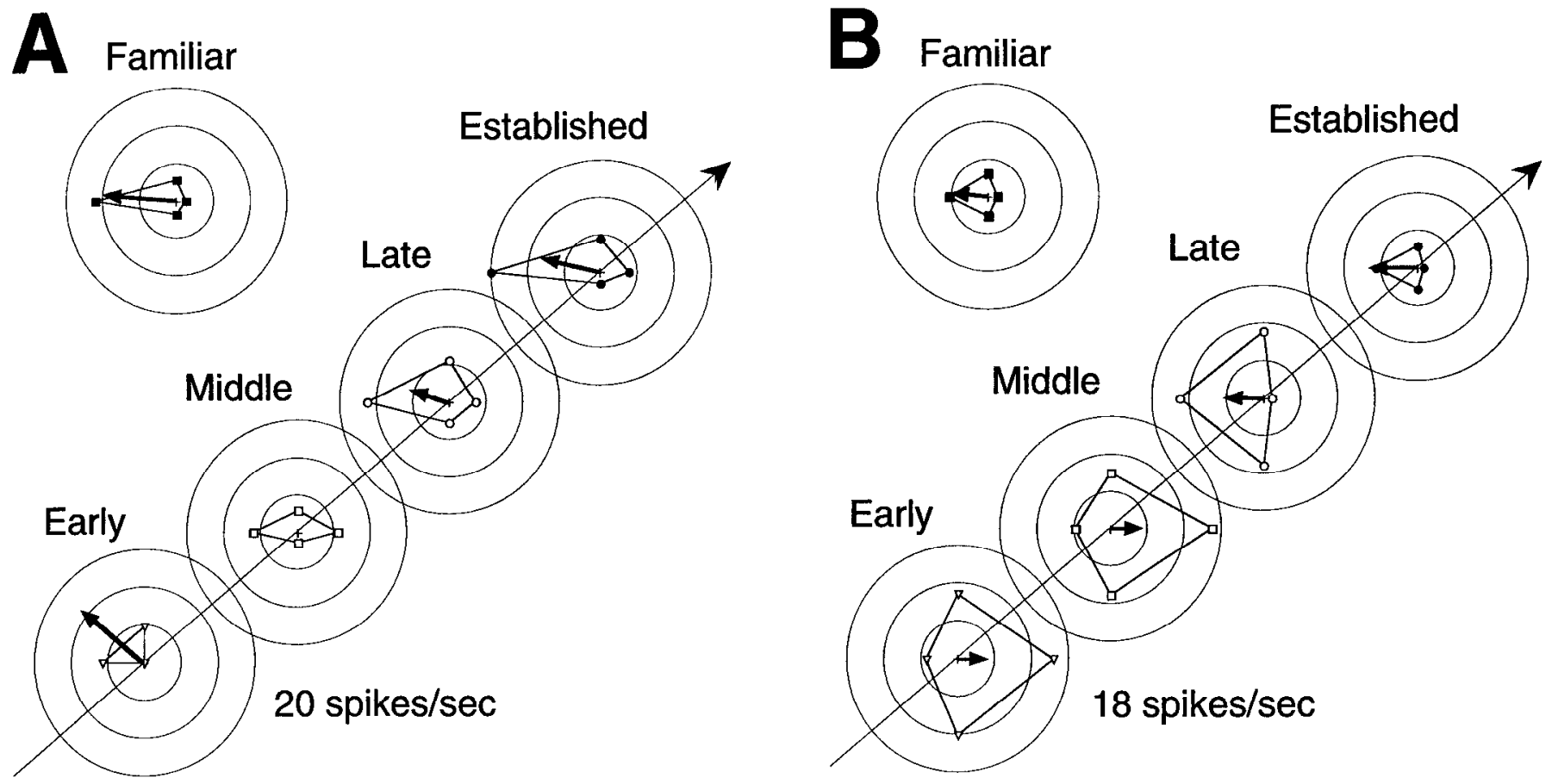

Figure 5. Directional tuning of two learning-dependent, directional SEF cells. $A$, Polar plots of the directional tuning of a cell, instructed by the familiar IS (top left) and the dircctional tuning in cach lcarning phase for novel IS trials, plottcd from lower left to upper right in a row along an arrow. Data were obtained in postsaccadic period. The bold arrow in each learning phase indicates the length and angle of the mean vector. The vector length, ranging from 0 to 1 , is scaled relative to the outer circle of each plot. The activity scale is identical for all parts of $A$, and vectors with a length $<0.2$ are not plotted. Note that the mean vectors in the late and established learning phases point in the direction similar to that of the familiar IS trials. $B$, Directional tuning of a different learning-dependent, directional SEF cell. Note that this cell decreases its modulation for the nonpreferred directions rather than increasing modulation for PDs. Data were obtained in the instructed delay period. Format as in $A$.

The gradual development of that cell's PD can be appreciated best from Figure $4 D$, which plots instruction-period activity during early, middle, and late phases of learning, and at the end of recording (the established period). In the early phase of learning, the activity during novel IS trials was relatively low for all saccade directions. However, by the late and established phases, discharge rates had risen dramatically, mostly for downward, but, to a lesser extent, also for rightward saccades. During those later learning phases, the PD for the four novel ISs resembled that observed for the four familiar ISs (Fig. $4 \mathrm{D}, \mathrm{fml}$ ). The PDs for familiar IS trials remained consistent during learning: $320^{\circ}$ during early phase, $290^{\circ}$ during middle phase, $304^{\circ}$ during late phase, and $299^{\circ}$ during established phase of learning. These PDs fell within the $99 \%$ confidence limit $\left(309 \pm 25^{\circ}\right)$, calculated from the familiar IS trials during the entire block (Batschelet, 1981). Iowever, the PDs for novel ISs showed dramatic changes during learning: $185^{\circ}$ during the early phase, $18^{\circ}$ during the middle phase, $294^{\circ}$ during the late phase, and $288^{\circ}$ during the established phase of learning. The PDs for novel IS trials during early and middle phases of learning significantly deviated from those for familiar PDs $(p<0.01)$, whereas those from the late and established phases did not.

\section{Cells with PDs for familiar IS trials}

Learning-dependent cases were defined on the basis of two factors: they showed both a significant time trend in modulation during learning (i.e., for sequential, correctly executed novel IS trials), and they had significant task-related activity on familiar IS trials [see Chen and Wise (1995a) for a more detailed definition].
I earning-dependent cases that showed a significant PD for familiar IS trials will be analyzed in this section. There were 22 of those cases obtained from 14 cells for which at least one novel IS was adequately tested in each of four saccade directions. They showed no apparent difference in the magnitude of their directional biases or preferred hemitield.

Of the 22 cases that showed a PD for familiar IS trials, six (27\%) showed a similar PD for novel IS trials during the early phase of learning. In each of those six cases, the PDs for novel IS trials remained, throughout learning, within $\pm 30^{\circ}$ of those observed in the familiar IS trials (Fig. $5 \mathrm{~A}$ ). However, in 16 of those 22 cases (73\%), the PDs for novel IS trials shifted during learning (Fig. $5 B$ ), especially in its early and middle phases. Gradually, over the course of learning, the novel IS PDs came to resemble those for familiar IS trials. By the middle phase of learning, nine cases $(41 \%)$ had novel IS PDs within $\pm 30^{\circ}$ from the PD of familiar IS trials. By the late phase, 14 of $22(64 \%)$ did so, and by the established phase, 17 of $22(77 \%)$ cases had novel IS PDs within $30^{\circ}$ of the familiar IS PD (Fig. 64).

To further assess the evolution of directional modulation during conditional oculomotor learning, the circular mean vector was calculated (Batschelet, 1981). Figure $6 A$ shows for each case the absolute value of the angular difference of the circular mean vectors (familiar vs novel IS trials). The novel IS PD deviated from the familiar IS PD by a mean of $65^{\circ}$ in the early phase of learning, $53^{\circ}$ in the middle phase, $30^{\circ}$ in the late phase, and $29^{\circ}$ by the end of recording (the established phase). Thus, 


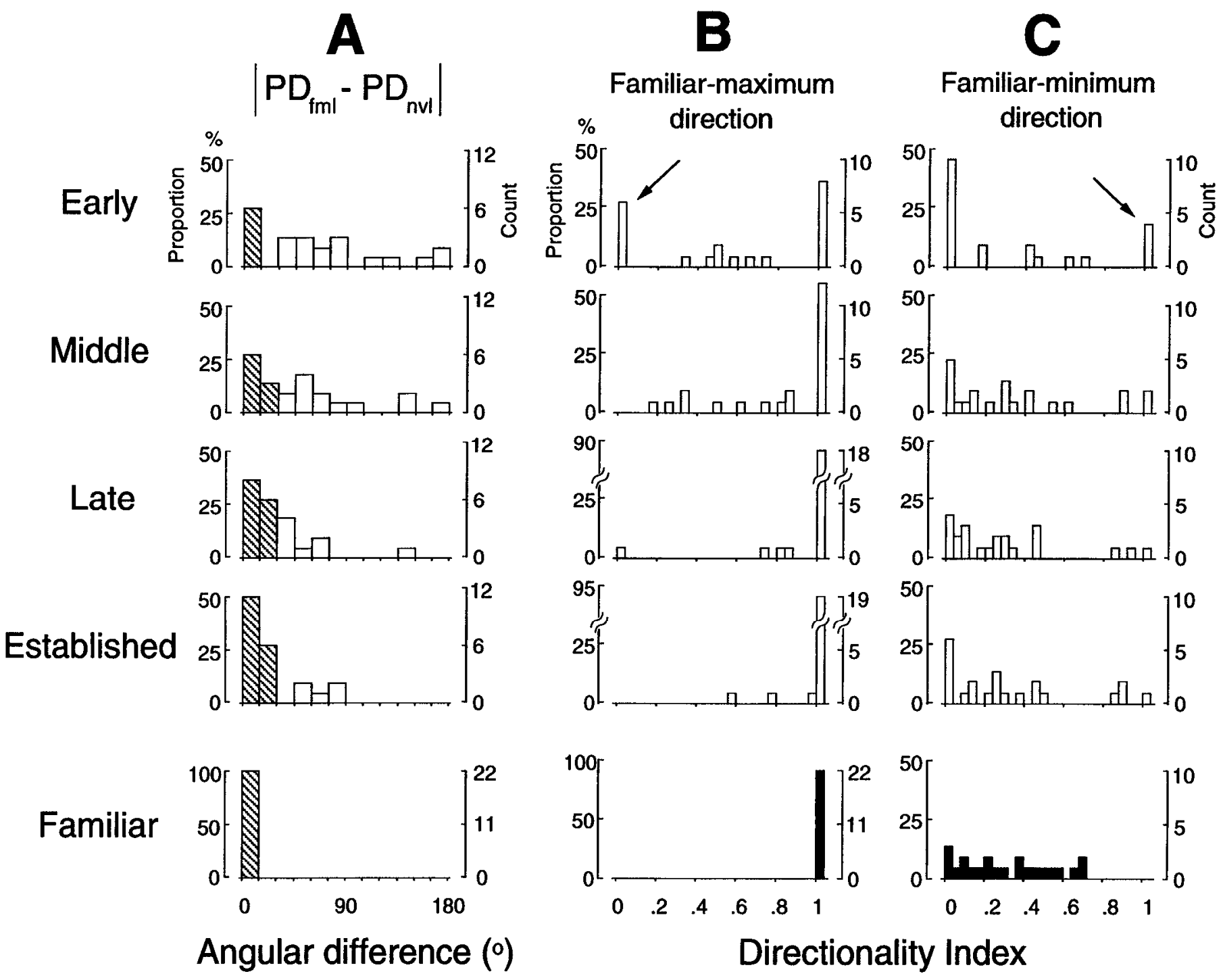

Figure 6. PD evolution during different learning phases. Data shown are from learning-dependent cases with a significant PD for familiar IS trials. $A$, Distribution, for each case, of the absolute value of the angular difference between the PD for familiar IS trials and that for novel IS trials in each learning phase. The hatched bars show the cases with absolute angular differences of $\leq 30^{\circ} . B$, DI, in each learning phase, for the direction of saccade that is associated with the strongest modulation in familiar IS trials (familiar-maximum direction). $C$, DI, in each learning phase, for the direction of saccade associated with the least activity in familiar IS trials (familiar-minimum direction). fml, Familiar; nvl, novel; $P D$, preferred direction.

during learning, the PDs shifted toward that observed in familiar IS trials.

A directionality index $(D I)$ (Fig. $6 B$ ) was also calculated for each case. Distributions of the $D I$ were calculated for two directions, both based on familiar IS trials. The saccade direction associated with the most activity on familiar IS trials was termed the familiar-maximum direction (Fig. $6 B$ ). The familiar-minimum direction was the saccade direction associated with the least discharge on familiar IS trials (Fig. 6C). Thus, the familiarmaximum direction resembled the $\mathrm{PD}$, but does not take into account the weight of activity for other saccade directions. For each phase of learning (early, middle, late, and established):

$$
D I=A_{\mathrm{FM}} / A_{\mathrm{L}},
$$

where $A_{\mathrm{FM}}$ is the activity rate associated with the familiarmaximum (Fig. $6 B$ ) or familiar-minimum (Fig. $6 C$ ) direction for that phase of learning, and $A_{\mathrm{L}}$ is the largest activity in the same learning phase. Consider, for example, a case in which the familiar-maximum is $60 \mathrm{impulses/sec} \mathrm{for} \mathrm{rightward} \mathrm{saccade} \mathrm{trials.}$ If the highest activity in a learning phase is $30 \mathrm{impulses} / \mathrm{sec}\left(A_{\mathrm{L}}\right)$ and it is also for rightward saccades $\left(A_{\mathrm{FM}}\right)$, then $D I=30 / 30=1$. Thus, in Figure $6 B$, a $D I$ of 1 indicates that the saccade direction associated with the maximal discharge rate for that phase of learning is the same as for familiar IS trials, regardless of the absolute level of activity. A $D I$ of 0 in Figure $6 B$, of which there are six cases in the early phase of learning (arrow), indicates complete inactivity on novel IS trials for the saccade direction that will be the maximum on familiar IS trials. DIs between 0 and 1 denote that there is some activity associated with the familiarmaximum direction, although it is less than that for some other saccade direction. Note in Figure $6 B$ the shift in the $D I$ distribution as learning progressed. The mean $D I$ was $0.56,0.80,0.93$, and 0.97 in the early, middle, late, and established phases, respectively. The $D I s$ were significantly different among these different phases of learning (Kruskal-Wallis test, $p<0.0003$ ), but there was no significant difference between the established phase of learning 


\section{Learning-dependent- directional}

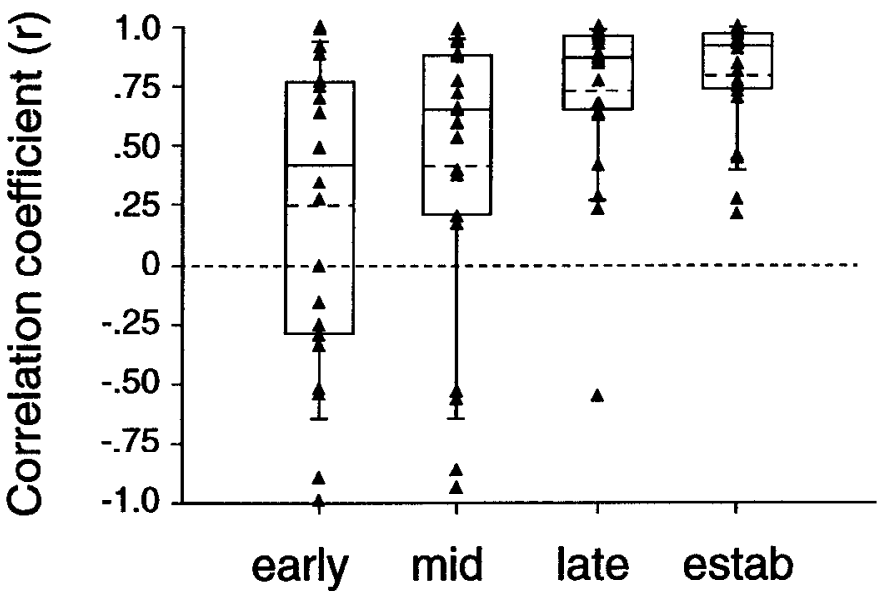

Figure 7. Correlation between the directional tuning on familiar IS trials and that of early, middle, late, and established phases for novel IS trials. Box plots show the median (solid line) and the mean (dashed line) for each phase, confined by the 25 th and 75 th percentile. The capped lines indicate the 10th and 90th percentiles.

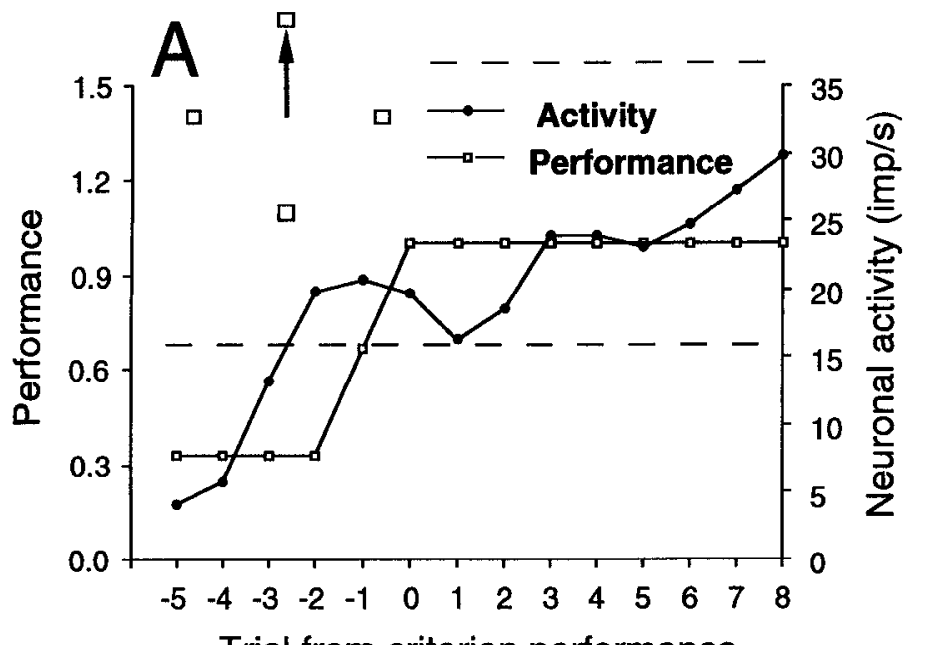

Trial from criterion performance

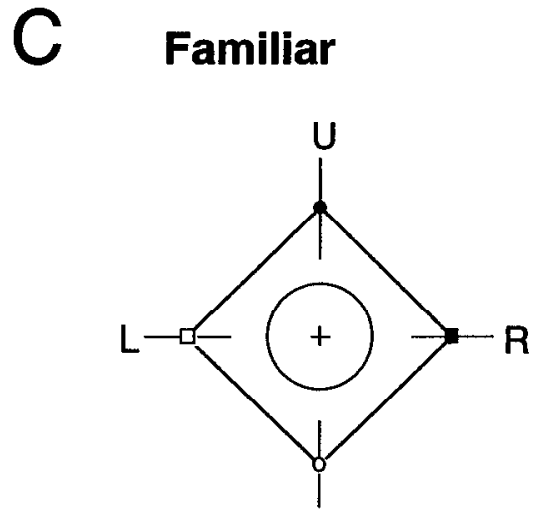

D and familiar IS trials. Figure $6 C$ shows a similar analysis for the saccade direction associated with the least discharge during familiar IS trials. Note that during the learning process there are a number of cases with substantial activity in familiar-minimum direction, and that, occasionally, the direction that is minimal for the familiar IS is maximal during learning (arrow in Fig. 6 C).

A correlational analysis of the same data is illustrated in Figure 7. We calculated the Pearson's correlation coefficient $(r)$ for the mean activity associated with each saccade direction in familiar IS trials versus the same directions for each of the learning phases. The correlation coefficient was 0.25 for familiar IS trials versus the early phase of learning, 0.42 versus the middle phase, 0.73 versus the late phase, and 0.80 versus the established phase. These statistical differences, based on the z-transformed $r$ values, were highly significant $\left(F_{(3,84)}=6.19 ; p<0.007\right)$. Post hoc tests (Schcffé's test, $p<0.05$ ) showed that the difference could be attributed to the comparisons of early versus late, early versus established, and middle versus established phases. Note that most cases eventually, by the end of the learning phase, adopted a fairly close correlation with the directionality in familiar IS trials, although a few outliers can be observed (Fig. 7, right).

The result of this correlational analysis agreed with the confidence-limit test, outlined above (see Batschelet, 1981) in 22 directional cases tested against the $99 \%$ confidence limit for the
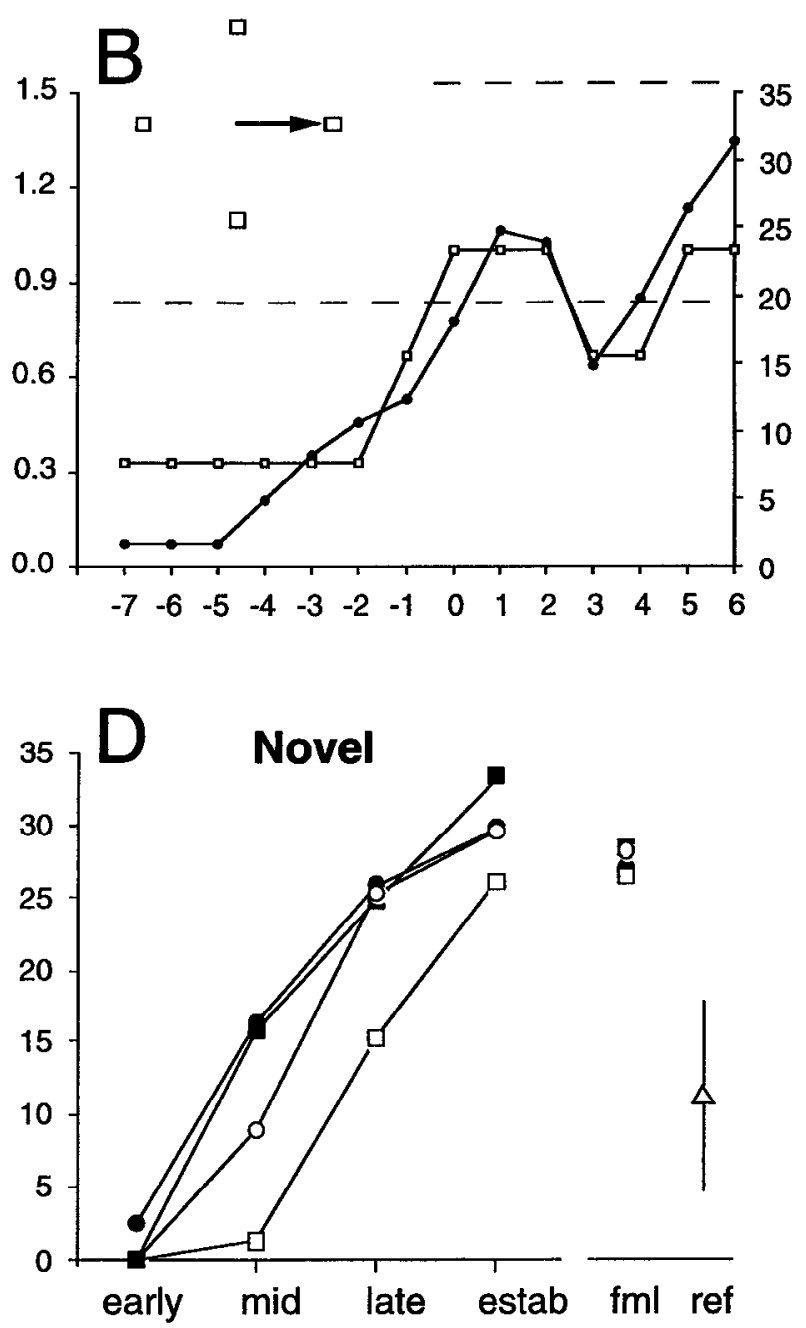

Figure 8. Activity modulation of an omnidirectional, learning-dependent SEF cell. Format as in Figure 4, except part $C$ shows only a polar plot of block averages. Data obtained from the postsaccadic period. 


\section{Learning Dependent- Omnidirectional Cells}
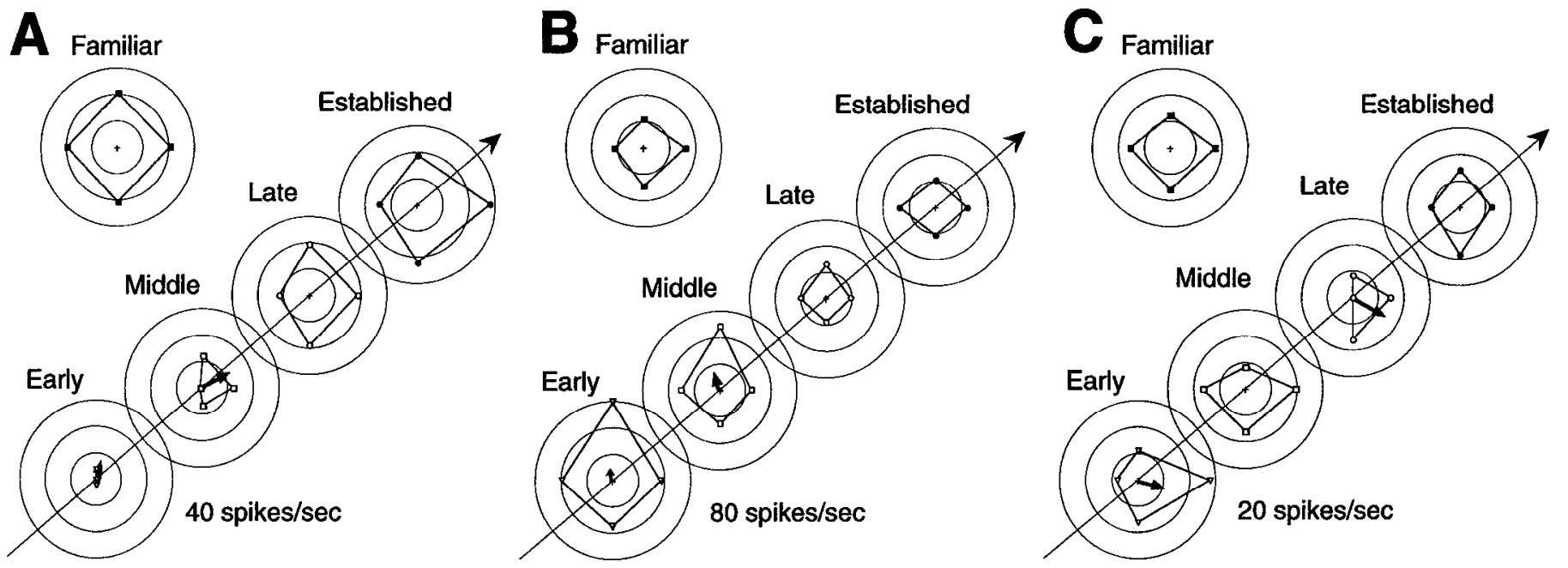

Figure 9. PD evolution of three SEF cells with learning-dependent, omnidirectional activity. Data for each cell is from a different task period: the postsaccadic $(A)$, target-hold $(B)$, and presaccade $(C)$ periods, respectively. Note that, regardless of the strength of modulation, transitory PDs emerged during the early phases of learning. Format as in Figure 5.

PDs in familiar IS trials. During early phase of learning, 12 cases had PDs for novel IS trials that deviated from that confidence limit. Twelve, seven, and three cases remained outside those limits during the middle, late, and established phases, respectively. These results indicate that the PDs on novel IS trials eventually converge on those for familiar IS trials. When the PDs for familiar IS trials were calculated for each learning phase, they were highly consistent, with nearly all of them $(20,19,21$, and 21 of 22 cases during the early, middle, late, and established phases, respectively) within the $99 \%$ confidence limit for all correctly executed, familiar IS trials. We also performed the confidence-limit test on the data as chronologically acquired, i.e., without the performance-based alignment inherent in the designation of early, middle, and late phases of learning. We examined activity in the first correctly executed trial (for each saccade direction), a subsequent set of five trials (the 2nd through 6th correct trials), the next five (the 7th through 11th), and the last two trials. For familiar IS trials, PDs fell within the $99 \%$ confidence limit in $20,19,21$, and 21 cases for those four time bins, respectively. For novel IS trials, $10,10,15$, and 18 cases showed such PD stability in the corresponding chronological time windows. Note that a similar pattern of PD lability occurred when comparing the chronological and performance-aligned analyses: $12,12,7$, and 4 cases lacked stability (i.e., fell outside the $99 \%$ confidence limits) in the former analysis, whereas $12,12,7$, and 3 did so in the latter, as learning progressed.

\section{Omnidirectional Cells}
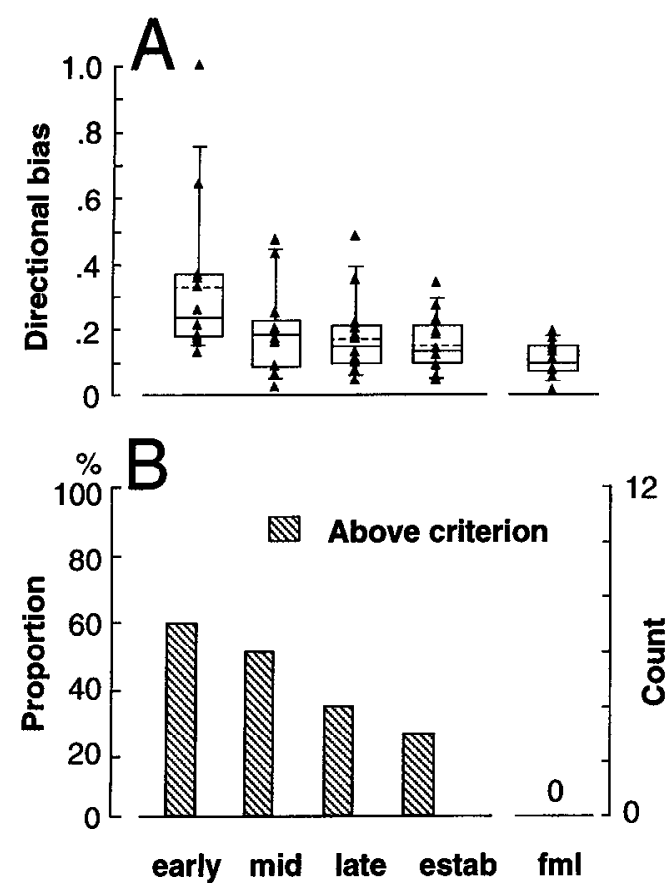

\section{Directional Cells}
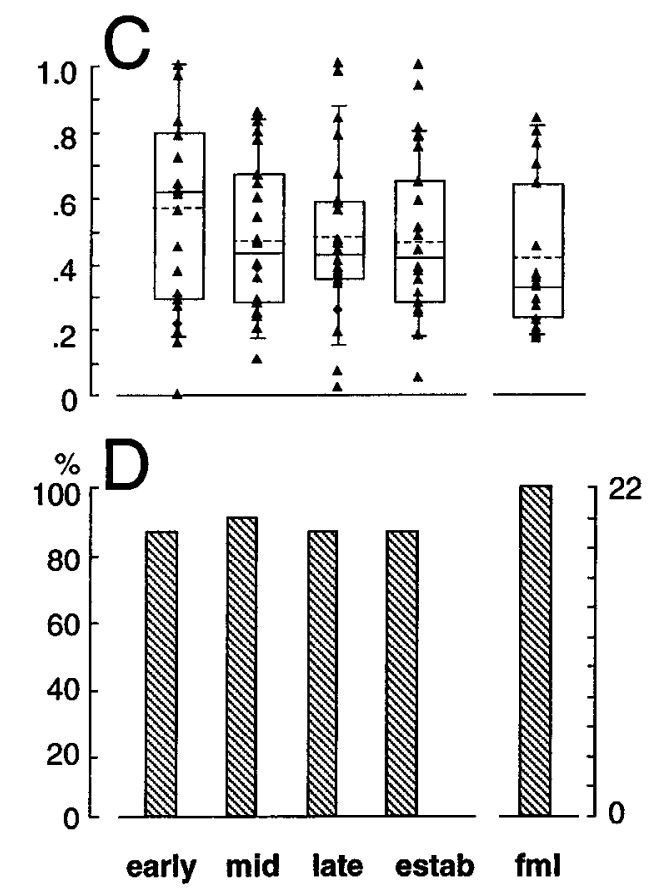

Figure 10. Magnitude of directional bias based on mean vector length $(A$ and $C$ ) and proportion of cases with directional biases during different learning phases $(B$ and $D)$. Data from learning-dependent cases lacking PDs for familiar IS trials $(A$ and $B)$ and those from learning-dependent cases with PDs on familiar IS trials $(C$ and $D)$ are displayed separately. Box plots show the median (solid line) and the mean (dashed line) for each phase, confined by the 25 th and 75 th percentile. The capped lines indicate the 10th and 90 th percentiles. Bar charts $(B$ and $D$ ) illustrate the proportion and number of cases showing a significant PD during each learning phase based on a cutoff criterion of 0.2 , a value that separated directional cases from omnidirectional ones for the familiar IS trials. mid, Middle phase of learning to respond to initially novel ISs; $f m l$, familiar IS trials. 

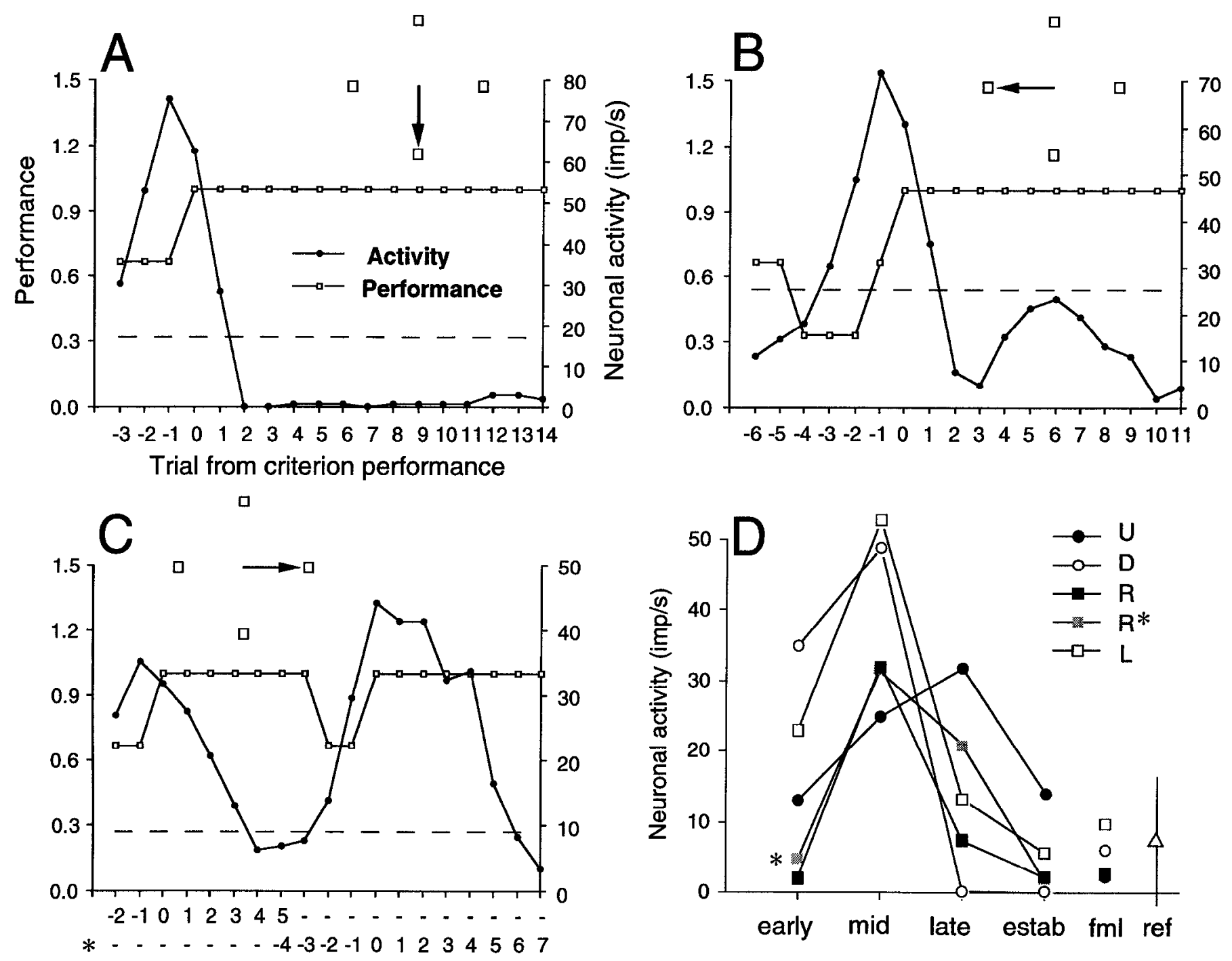

Figure 11. Activity modulation of a learning-selective SEF cell. Format as in Figure 4. For the novel IS associated with rightward saccades, the monkey had two distinct phases of learning, as shown in $C$. Asterisks in $C$ and $D$ indicate the trials that are normalized to the second attainment of criterion performance for rightward saccades. Dashed horizontal lines indicate +1 SD of the mean activity for the familiar IS trials, for the same saccade direction. -1 SD lines, not shown, are $<0$ impulses $/ \mathrm{sec}$. Data were obtained from the instructed delay period.

The cases that have significant PDs for familiar IS trials almost always show some directional bias during learning (see Fig. $10 C, D)$, although, as illustrated in Figure $5 B$, the direction of that bias may change. The vast majority $(86-91 \%)$ of the cases exhibited directional biases $\geq 0.2$, a cut-off value that separated the directional cases from the omnidirectional ones (see Fig. 10D) for familiar IS trials. Among these cases, 17 of $23(74 \%)$ showed a PD during all phases of learning. Thus, PDs change during learning rather than disappear for substantial perinds. Figure $10 \mathrm{C}$ shows that the magnitude of directional bias was not different among the learning phases (Kruskal-Wallis test, $p>0.4$ ), with the average mean vectors ranging between 0.47 and 0.57 . A cell-by-cell analysis confirmed the case-by-case analysis described here (also see Table 1).

\section{Cells lacking PDs for familiar IS trials}

As noted in the previous section, some learning-dependent cases showed PDs for familiar IS trials, whereas others did not. These omnidirectional, learning-dependent cases were significantly modulated relative to reference-period activity, but lacked signif- icant directional biases for familiar IS trials. Another class showed no task-related activity for familiar IS trials and, therefore, also lacked PDs on those trials. In the terminology of Chen and Wise (1995a), those cases are termed "learning-selective." Figure 8 shows the evolution of neuronal activity of an SEF cell with omnidirectional discharge for familiar IS trials. Much like the cell illustrated in Figures 3 and 4, the activity of this neuron rose in parallel with the improvement of performance, at least during the early and middle phases of learning. Note that the activity levels for the some saccade directions differed from the others in earlier phases (Fig. 8D): discharge for leftward saccade trials was essentially zero in the middle phase of learning, but that for upward and rightward saccade trials was $\sim 15$ impulses/sec. By the time of the established phase of learning, activity for leftward trials remained slightly but insignificantly less than that for the other directions, and activity for novel IS trials in all saccade directions fell in the 25-35 impulses/sec range. The mean vector length was 0.43 in the middle phase of learning but only 0.11 in the established phase. Thus, in the early phases of learning, the cell exhibited a transitory 


\section{Learning Selective Cell}

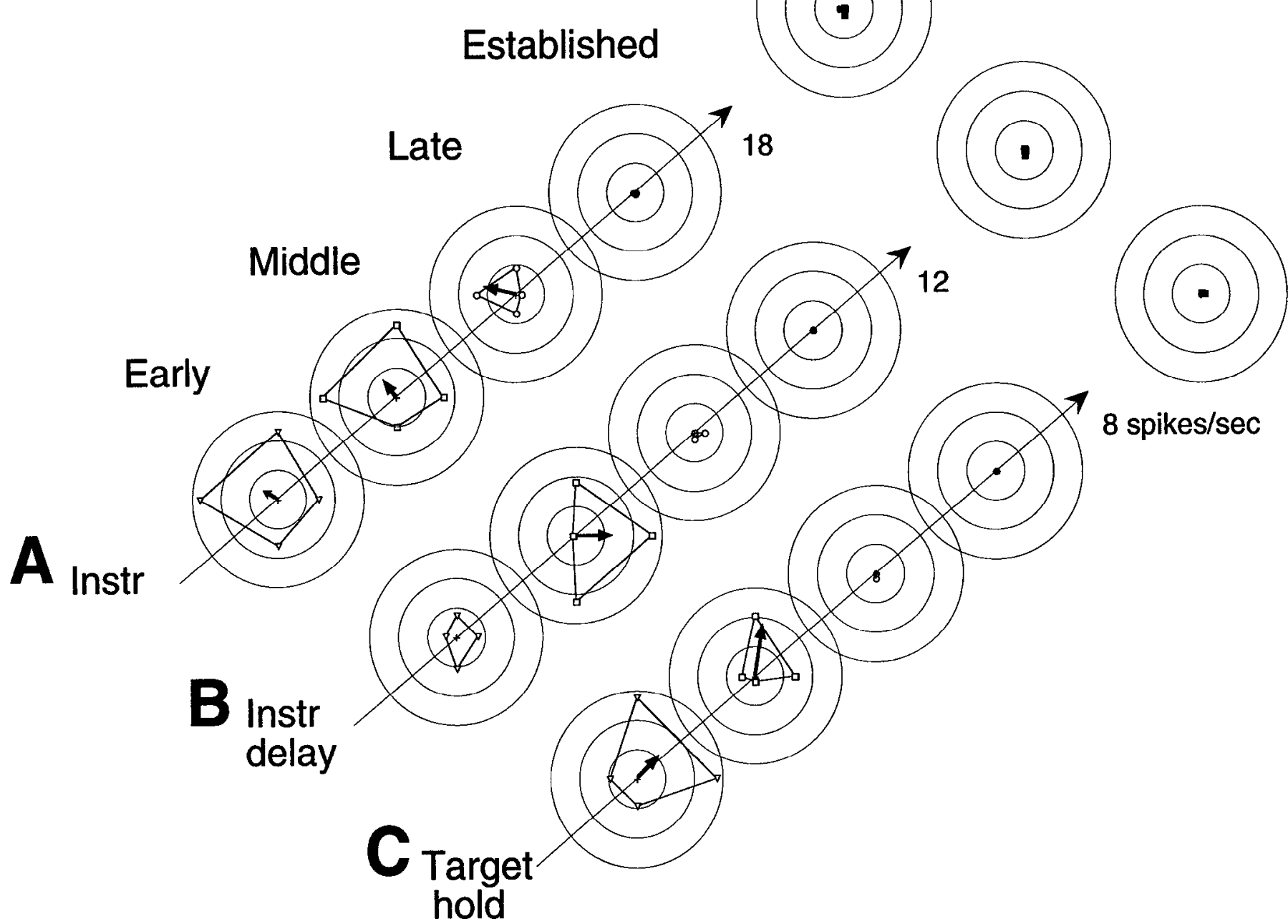

Figure 12. Polar plots for a learning-selective SEF cell, with activity modulation during instruction period $(A)$, instructed delay period $(B)$, and postsaccadic target hold period $(C)$, respectively. Note that the PD can be dramatically different in different task periods. Format as in Figure 5.

directional bias. Later, the directional bias dissipated to negligible levels. The cell retained an omnidirectional tuning for familiar IS trials (Fig. $8 \mathrm{C}$ ) throughout learning, with some fluctuation, but with a consistently low mean vector length $(\leq 0.08)$ in all phases.

Transitory directional biases appear to be the rule rather than the cxccption (Fig. 9). Wc asscssed 12 learning-dependent cases (obtained from 8 cells) for which all four directions could be adequately tested. None of these cases showed PDs for the familiar IS trials. However, all of these cases showed a transient PD during the course of learning. Figure $10 \mathrm{~A}$ illustrates the magnitude of directional bias for this neuronal subpopulation. The average mean vectors were 0.33 for the early learning phase, 0.19 for the middle phase, 0.18 for the late phase, and 0.15 for the established phase. There were significant differences among the learning phases (Kruskal-Wallis test, $p<0.01$ ). The post hoc analyses indicated that the difference could be attributed to the early versus late phases (Mann-Whitney $U$ test, $p<0.04$ ), early versus established phases $(p<0.02)$, and early phase versus familiar IS trials $(p<0.0004)$. Figure $10 B$ illustrates the proportion of cases having transient PDs $\geq 0.2$ in each phase of learning: $58 \%$ for the early phase of learning, which decreased to $50 \%$ by the middle phase; $33 \%$ by the late phase; and $25 \%$ by the established phase. Together, the measures show that these cells were directional during the early phases of learning, but later decreased their directional biases. Examples were found in all task periods.

Figure 11 illustrates the activity of a learning-selective case. As with learning-dependent activity, learning-selective activity increased, at first, in parallel with the improvement of performance (Fig. 11A,B). However, unlike learning-dependent cases, this learning-selective activity eventually ceased to differ significantly from reference-period activity. Note that when the activity increased, it peaked at different activity levels for different saccade directions (Fig. 11D). Another learning-selective cell is illustrated in Figure 12. That cell also showed transient PDs during learning. Twenty-four learning-selective cases, obtained from 16 cells, could be adequately tested. We defined directional biases as cases with mean vectors of at least 0.2 and activity $>3$ impulses/sec for at least one saccade direction. By these criteria, all but one case showed a transient novel IS PD during the course of learning. Directional biases occurred progressively less frequently as the behavior was acquired. Fourteen of 24 (58\%) cases were directionally biased in the early, 11 of $24(46 \%)$ in the middle, and 8 of 


$$
\text { A }
$$

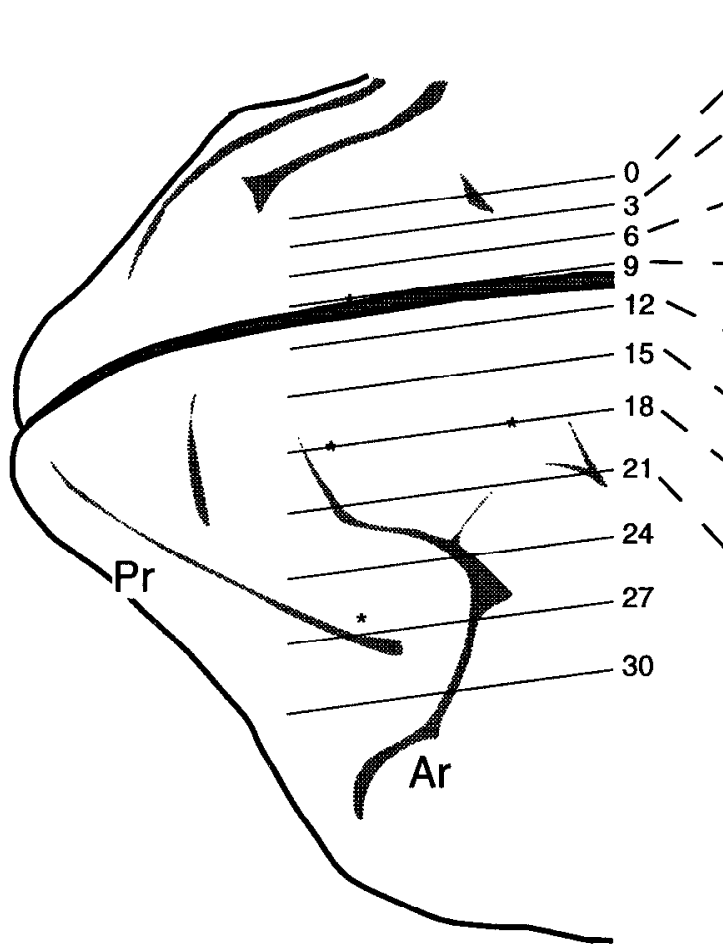

B

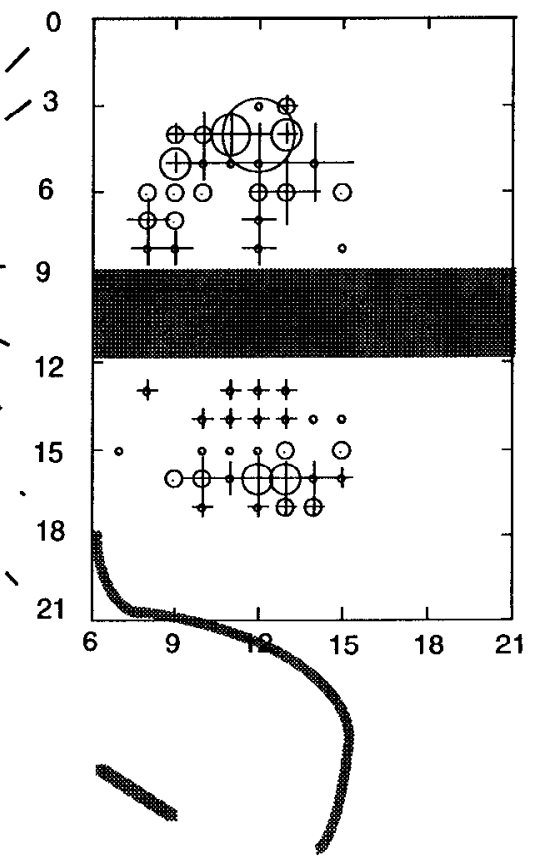

C

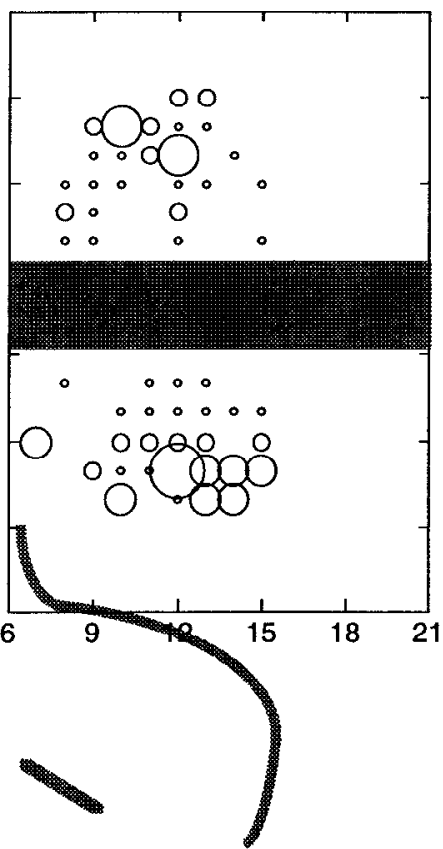

Figure 13. A, Lateral view of the cortical surface from the second monkey examined in this study. B, Proportional distribution of directional (open circles) and omnidirectional (plus signs) cases of learning-dependent activity. $C$, Distribution of learning-selective cases (open circles). In $B$ and $C$, the size of the symbol is proportional to the number of cases in each class. Ar, Arcuate sulcus; Pr, principal sulcus.

$24(33 \%)$ in the established phases. Examples were found in all task periods.

In 23 nondirectional cases tested for familiar IS trials, only 2 cases had mean vectors of at least 0.2 and activity $>3$ impulses/sec during the early phase of learning. Four, five, and five cases exceeded those limits during middle, late, and established phases, respectively. These results indicate that cells rarely showed a substantial PD on familiar IS trials during any phases of learning, in contrast to their behavior during interleaved novel IS trials during the same time periods.

\section{Localization}

Figure $13 B$ shows the location of penetrations yielding learningdependent cases with versus without PDs for familiar IS trials. The learning-selective cases that make up the present data set are depicted in Figure $13 \mathrm{C}$. The locations of these surface projections can be referenced to electrode tracks reconstructed in Figure 15 of Chen and Wise (1995a).

\section{DISCUSSION}

\section{PD lability}

Conditional motor learning confers the ability to link any discriminable stimulus with any response. The evolution of PDs during learning may reflect a reorganization of the premotor network that underlies this highly flexible selection process, and PD lability may represent changes in afferent associative strength. This interpretation has been emphasized in computational models of conditional motor learning (Fagg and Arbib, 1992; Dominey et al., 1995), which show similar changes in neuronal discharge rates and directional selectivity as the network learns an arbitrary stimulus-response relationship. In those models, inputs reflecting visual stimuli are flexibly linked with output modules that contribute to movements in a given direction. As the network learns to produce a winner-takes-all output in response to an arbitrary input, the synaptic weights between that input and the appropriate network outputs increase, whereas others decrease. A leftward saccade output unit might "respond" to a rightward IS early in learning, although it contributes an (outvoted) leftward vector to the network's output computation. Later, as learning consolidates, the afferent weights to the unit change to evoke greater activity for leftward ISs (and less for rightward ISs), which causes the unit to contribute more appropriately to the network's output. This evolution in afferent drive would appear as a change in PD as it is usually calculated. Thus, the lability of PDs in SEF does not imply that the effective (or motor) output of the cells changes with experience, although that remains a possibility. Another possibility is that the PDs represent motor efference copy that can be used in local, unsupervised training processes. We will not speculate further about the causal mechanisms underlying these flexible stimulus-response transformations, but we note that any theory of such behavior should account for the observed lability in PDs.

In the primary motor cortex, the directional tuning of individual neurons supports the computation of a population vector, a transformed directional signal based on an activity-weighted circular average of a cell population (Georgopoulos et al., 1983, 1989, 
1992). In the calculation of a population vector, each cell's weighted contribution for a given movement direction is predicted with respect to that neuron's PD. Ignoring, for the sake of discussion, any potential differences between cortical areas and behavioral tasks, the finding of pervasive lability in the PDs of individual SEF neurons suggests that the computational basis for a population vector changes dramatically during learning.

\section{Context dependency}

Because the neuronal discharge was correlated with saccadic eye movements in a context-dependent manner (e.g., early but not later during lcarning), the neural signals we observed are unlikcly to reflect simple motor command signals, even for discharge modulations that occur immediately before the saccade and are time-locked to it. Similarly, because the activity differs significantly when a given novel IS appears early versus late in learning, the activity modulation is unlikely to reflect sensory information processing, per se, even in those neurons for which the neural signal shortly follows and is time-locked to the stimulus presentation. Thus, PD lability during conditional oculomotor learning provides further cause to reject interpretations of neuronal activity based solely on temporal correlation with events (see Boussaoud and Wise, 1993; di Pellegrino and Wise, 1993; Vaadia et al., 1995). These considerations reinforce the view that neuronal activity in premotor cortex, construed generally to include oculomotor and skeletomotor areas, reflects the instructional significance of stimuli in a particular behavioral context, regardless of when, during a trial, that activity occurs.

Mann et al. (1988) reported that operantly conditioning monkeys to make saccades to a fixed spatial array of targets biased the effects of microstimulating SEF (which they term the dorsomedial frontal cortex). Most of the microstimulation-evoked saccades were directed toward the targets of the conditioned array. We did not attempt microstimulation during conditional oculomotor learning. Nevertheless, our results agree, in general, with the thesis proposed by Mann et al. (1988). SEF PDs are labile and dramatically affected by both experience and context, and they converge on PDs for the well learned, familiar stimuli as a novel stimulus-response association becomes consolidated.

\section{Role of omnidirectional and learning-selective neurons}

It is generally assumed that omnidirectional neurons, i.e., those lacking PDs, are uninvolved in the neural network responsible for selection of movement direction. As we demonstrate here, neurons with such properties may have PDs transiently during conditional oculomotor learning. Thus, these cells may participate in the process of selecting movement direction, especially during periods of stimulus-response learning. As we have pointed out previously (Chen and Wise, 1995a), the learning-selective activity may play a transitory role in selection of movement direction during learning or when a response must be selected on some basis other than a learned stimulus-response association. We also note that a significant population of SEF neurons do not show learning-related changes, and thus will yield no modulation in their PDs (Chen and Wise, 1995a).

\section{Interpretational issues}

Saccadic eye movements were highly stereotyped in all directions, and reaction time was almost constant, regardless of saccade direction. There was no significant change in gaze stability at either the origin or any of the targets. There were some modulations of muscle activity in this oculomotor task, but none of them showed significant differences among saccade directions. Thus, we conclude that none of these factors contributed to our result.

The task design limited the influence of selective attention or different coordinate frames. During the task, the monkey had to attend to two sensory events: the visual IS and the disappearance of the fixation point. Both occur at the center of the screen and at the fovea. Thus, it is likely that the visual attention was centrally directed. The stability of reaction time during learning, regardless of saccade direction, argues against any systematic variation in attention with particular movement directions or during learning. And, because the monkey's head was fixed and gaze controlled, the location of stimuli was constant in all relevant coordinate systems. Thus, variations in spatial coordinate frames [e.g., craniocentric versus retinncentric systems (Schlag and Schlag-Rey, $1987 b$ ) or object-centered versus viewer-centered references (Olson and Gettner, 1995)] could not have affected our results.

Our main method for calculating PD involved aligning the data for each saccade direction on the attainment of criterion performance. One might object that we never calculated the $\mathrm{PD}$ at any point in chronological time and, therefore, that baseline activity might change the apparent PD. I Iowever, this potential difficulty is less significant than it might appear. First, the learning rate for each novel stimulus correlated fairly well during learning. Second, the early and established learning phases consisted of the first trial and the last two trials in a learning block, respectively, which were unaffected by our performance-based alignment method. Thus, our two principal conclusions (that PDs change or disappear during learning) do not depend on the averaging method chosen. Performance-based alignment seems to us the most reasonable method for estimating the PD without biasing the estimate with effects of performance level. The possibility that cells either became generally inactive, artifactually excited, or inadequately isolated during learning was examined closely. Both familiar and novel ISs, instructing the same saccade directions, were presented pseudorandomly in interleaved trials within the same learning session. The relative stability of the activity associated with the familiar IS and the lack of systematic change in reference-period activity argues strongly against the possibility that PD shifts resulted from a change in cell excilability (baseline drift) or from poor isolation.

Two additional issues bear careful scrutiny. Differences between familiar and novel IS activity, including PD, could result from features of the visual stimuli involved or from variation reflecting the small number of trials in each learning phase. Stimulus feature coding cannot explain the evolution of discharge modulation during learning because the stimulus and response were identical for the first and last correctly executed trials (see Fig. $3 D$ ). Further, as learning progressed, activity levels and directional biases for novel IS trials tended to converge on those for familiar IS trials. And the small number of trials in each learning phase was not responsible for our result: familiar IS PDs showed relatively constant properties when calculated for the same learning phases with comparable numbers of trials.

\section{Conclusion}

The PD lability reported here reinforces the notion that, in SEF and in other premotor areas (Aizawa et al., 1991; Mitz et al., 1991; Germain and Lamarre, 1993), activity levels and patterns change rapidly during learning. Conditional motor learning, which typically involves the mapping of nonspatial information onto spatially directed motor acts, reflects the most flexible of stimulusresponse associations. The ability to rapidly form and break such 
associations, thus to change in the short term the behavioral significance of sensory events, may underlie the central adaptive advantage conferred on the individual by premotor areas of the frontal lobe.

\section{REFERENCES}

Aizawa H, Inase M, Mushiake H, Shima K, Tanji J (1991) Reorganization of activity in the supplementary motor area associated with motor learning and functional recovery. Exp Brain Res 84:668-671.

Ashe J, Georgopoulos AP (1994) Movement parameters and neural activity in motor cortex and area 5. Cereb Cortex 6:590-600.

Ashe J, Taira M, Smyrnis N, Pellizzer G, Georgakopoulos T, Lurito JT, Georgopoulos AP (1993) Motor cortical activity preceding a memorized movement trajectory with an orthogonal bend. Exp Brain Res 95:118 - 130 .

Barash S, Braccwcll RM, Fogassi L, Gnadt JW, Anderscn RA (1991) Saccade-related activity in the lateral intraparietal area. II. Spatial properties. J Neurophysiol 66:1109-1124.

Batschelet E (1981) Circular statistics in biology. New York: Academic.

Bon L, Lucchetti C (1992) The dorsomedial frontal cortex of the macaca monkey: fixation and saccade-related activity. Exp Brain Res 89:571-580.

Bon L, Lucchetti C (1994) Ear and eye representation in the frontal cortex, area 8b, of the macaque monkey: an electrophysiological study. Exp Brain Res 102:259-271.

Bosco G, Poppele RE (1993) Broad directional tuning in spinal projections to the cerebellum. J Neurophysiol 70:863 866 .

Boussaoud D, Wise SP (1993) Primate frontal cortex: effects of stimulus and movement. Exp Brain Res 95:28-40.

Bruce CJ, Goldberg ME (1985) Primate frontal eye fields. I. Single neurons discharging before saccades. J Neurophysiol 53:603-635.

Buford JA, Anderson ME (1993) Preparatory and movement-related activity of neurons in pallidal-receiving thalamus. Soc Neurosci Abstr 19:1585.

Caminiti R, Johnson PB, Urbano A (1990) Making arm movements within different parts of space: dynamic aspects in the primate motor cortex. J Neurosci 10:2039-2058.

Caminiti R, Johnson PB, Galli C, Gerraina S, Burnod Y (1991) Making arm movements within different parts of space: premotor and motor cortical representation of a coordinate system for reaching to visual targets. J Neurosci 11:1182-1197.

Chen LL, Wise SP (1995a) Neuronal activity in the supplementary eye field during acquisition of conditional oculomotor associations. J Neurophysiol 73:1101-1121.

Chen LL, Wise SP (1995b) Supplementary eye field contrasted with the frontal eye field during acquisition of conditional oculomotor associations. J Neurophysiol 73:1122-1134.

Crammond DJ, Kalaska JF (1994) Modulation of preparatory neuronal activity in dorsal premotor cortex due to stimulus-response compatibility. J Neurophysiol 71:1281-1284.

di Pellegrino G, Wise SP (1991) A neurophysiological comparison of threc distinet regions of the primate frontal lobe. Brain 114:951-978.

di Pellegrino G, Wise SP (1993) Visuospatial vs. visuomotor activity in the premotor and prefrontal cortex of a primate. J Neurosci 13:1227-1243.

Dominey P, Arbib M, Joseph J-P (1995) Model of corticostriatal plasticity for learning oculomotor associations and sequences. J Cognitive Neurosci 7:311-336.

Evans FJ (1978) Monitoring attention deployment by random number generation: an index to measure subjective randomness. Bull Psychon Soc 12:35-38.

Fagg AH, Arbib MA (1992) A model of primate visual-motor conditional learning. J Adapt Behav 1:3-37.

Fortier PA, Kalaska JF, Smith AM (1989) Cerebellar neuronal activity related to whole-arm reaching movements in the monkey. J Neurophysiol 62:198-211.

Fu Q-G, Suarez JI, Ebner TJ (1993) Neuronal specification of direction and distance during reaching movements in the superior precentral premotor areas and primary motor cortex of monkeys. J Neurophysiol 70:2097-2116.

Funahashi S, Bruce CJ, Goldman-Rakic PS (1990) Visual spatial coding in primate prefrontal neurons revealed by oculomotor paradigms. J Neurophysiol 63:814-831.
Funahashi S, Bruce CJ, Goldman-Rakic PS (1991) Neuronal activity related to saccadic eye movements in the monkey's dorsolateral prefrontal cortex. J Neurophysiol 65:1464-1483.

Georgopoulos AP, Caminiti R, Kalaska JF, Massey JT (1982) On the relations between the direction of two-dimensional arm movements and cell discharge in primate motor cortex. J Neurosci 2:1527-1537.

Georgopoulos AP, Caminiti R, Kalaska JF, Massey JT (1983) Spatial coding of movement: a hypothesis concerning the coding of movement direction by motor cortical populations. Exp Brain Res Suppl $7: 327-336$.

Georgopoulos AP, Caminiti R, Kalaska JF (1984) Static spatial effects in motor cortex and area 5: quantitative relations in a two-dimensional space. Exp Brain Res 54:446-454.

Georgopoulos AP, Lurito JT, Petrides M, Schwartz AB, Massey JT (1989) Mental rotation of the neuronal population vector. Science 243:234-236.

Georgopoulos AP, Ashe J, Smyrnis N, Taira M (1992) The motor cortex and the coding of force. Science 256:1692-1695.

Germain L, Lamarre Y (1993) Neuronal activity in the motor and premotor cortices before and after learning the associations between auditory stimuli and motor responses. Brain Res 611:175-179.

Gnadt JW, Bracewell RM, Andersen RA (1991) Sensorimotor transformation during eye movements to remembered visual targets. Vision Res 31:693-715.

Hanes DP, Thompson KG, Schall JD (1995) Relationship of presaccadic activity in the frontal cye ficld and supplementary cyc ficld to saccade initiation in macaque: Poisson spike train analysis. Exp Brain Res 103:85-96.

Hikosaka O, Wurtz RH (1983) Visual and oculomotor functions of monkey substantia nigra pars reticulata. III. Memory-contingent visual and saccade responses. J Neurophysiol 49:1268-1284.

Hikosaka O, Sakamoto M, Usui S (1989) Functional properties of monkey caudate neurons. I. Activities related to saccadic eye movements J Neurophysiol 61:780-798.

Johnson PB, Ferraina S, Caminiti R (1993) Cortical networks for visual reaching. Exp Brain Res 97:361-365.

Johnson PB, Ferraina S, Bianchi L, Caminiti R (1996) Cortical networks for visual reaching. Physiological and anatomical organization of frontal and parietal lobe arm region. Cerebral Cortex, in press.

Kalaska JF, Crammond DJ (1992) Cerebral cortical mechanisms of reaching movements. Science 255:1517-1523.

Kalaska JF, Caminiti R, Georgopoulos AP (1983) Cortical mechanisms related to the direction of two-dimensional arm movements: relations in parietal area 5 and comparison with motor cortex. Exp Brain Res $51: 247-260$

Kalaska JF, Cohen DAD, Hyde ML, Prud'homme M (1989) A comparison of movement direction-related versus load direction-related activity in primate motor cortex, using a two-dimensional reaching task. J Neurosci 9:2080-2102.

Kalaska JF, Cohen DAD, Prud'homme M, Hyde ML (1990) Parietal area 5 neuronal activity encodes movement kinematics, not movement dynamics. Exp Brain Res 80:351-364.

Kalaska JF, Crammond DJ, Cohen DAD, Prud'homme M, Hyde MI (1992) Comparison of cell discharge in motor, premotor, and parietal cortex during reaching. In: Control of arm movement in space: neurophysiological and computational approaches (Caminiti R, Johnson PB Burnod Y, eds), pp 129-146. Berlin: Springer.

Luppino G, Matelli M, Camarda RM, Gallese V, Rizzolatti G (1991) Multiple representations of body movements in mesial area 6 and the adjacent cingulate cortex. An intracortical microstimulation study in the macaque monkey. J Comp Neurol 311:463-482.

Lurito JT, Georgakopoulos T, Georgopoulos AP (1991) Cognitive spatial-motor processes. 7 . The making of movements at an angle from a stimulus direction: studies of motor cortical activity at the single cell and population levels. Exp Brain Res 87:562-580.

Mann SE, Thau R, Schiller PH (1988) Conditional task-related responses in monkey dorsomedial frontal cortex. Exp Brain Res 69:460-468.

Matelli M, Luppino G, Rizzolatti G (1991) Architecture of superior and mesial area 6 and the adjacent cingulate cortex in the macaque monkey. J Comp Neurol 311:445-462.

Mitz AR, Godschalk M, Wise SP (1991) Learning-dependent neuronal activity in the premotor cortex: activity during the acquisition of conditional motor associations. J Neurosci 11:1855-1872. 
Olson CR, Gettner SN (1995) Object-centered direction selectivity in the macaque supplementary eye field. Science 269:985-988.

Russo GS, Bruce CJ (1993) Effect of eye position with the orbit on electrically elicited saccadic eye movements: a comparison of the macaque monkey's frontal and supplementary eye fields. J Neurophysiol 69:800-818.

Schall JD (1991a) Neuronal activity related to visually guided saccades eye movements in the supplementary motor area of rhesus monkeys. J Neurophysiol 66:530-558.

Schall JD (1991b) Neuronal activity related to visually guided saccades in the frontal eye fields of rhesus monkeys: comparison with supplementary eye fields. J Neurophysiol 66:559-579.

Schall JD, Hanes DP (1993) Neural basis of saccade target selection in frontal eye field during visual search. Nature 366:467-469.

Schall JD, Morel A, Kaas J (1993) Topography of supplementary eye field afferents to frontal eye field in macaque: implications for mapping between saccade coordinate systems. Vis Neurosci 10:385-393.

Schlag J, Schlag-Rey M (1985) Unit activity related to spontaneous saccades in frontal dorsomedial cortex of monkey. Exp Brain Res 58:208-211.

Schlag J, Schlag-Rey M (1987a) Evidence for a supplementary eye field. J Neurophysiol 57:179-200.

Schlag J, Schlag-Rey M (1987b) Does microstimulation evoke fixedvector saccades by generating their vector or by specifying their goal? Exp Brain Res 68:442-444.

Schlag J, Schlag-Rey M, Pigarev I (1992) Supplementary eye field: influence of eye position on neural signals of fixation. Exp Brain Res 90:302-306.

Schwartz AB (1992) Motor cortical activity during drawing movements: single-unit activity during sinusoid tracing. J Neurophysiol 68:528-541.
Schwartz AB (1993) Motor cortical activity during drawing movements: population representation during sinusoid tracing. $\mathrm{J}$ Neurophysiol $70: 28-36$.

Schwartz AB (1994) Direct cortical representation of drawing. Science 256:540-542.

Schwartz AB, Kettner RE, Georgopoulos AP (1988) Primate motor cortex and free arm movements to visual targets in three-dimensional space. I. Relations between single cell discharge and direction of movement. J Neurosci 8:2913-2927.

Siegel S, Castellan NJ (1988) Nonparametric statistics for the behavior sciences. New York: McGraw-Hill.

Smyrnis N, Taira M, Ashe J, Georgopoulos AP (1992) Motor cortical activity in a memorized delay task. Exp Brain Res 92:139-151.

Tchovnik EJ, Lce K (1993) The dorsomedial frontal cortex of the rhesus monkey: topographic representation of saccades evoked by electrical stimulation. Exp Brain Res 96:430-442.

Tehovnik EJ, Lee K, Schiller P (1994) Stimulation-evoked saccades from the dorsomedial frontal cortex of the rhesus monkey following lesions of the frontal eye fields and superior colliculus. Exp Brain Res 98:179-190.

Tulving E (1962) Subjective organization in free recall of "unrelated" words. Psychol Rev 69:344-354.

Vaadia E, Benson DA, Hienz RD, Goldstein MH (1986) Unit study of monkey frontal cortex: active localization of auditory and of visual stimuli. J Neurophysiol 56:934-952.

Vaadia E, Haalman I, Abeles M, Bergman H, Prut Y, Slovin H, Aertsen A (1995) Dynamics of neuronal interactions in monkey cortex in relation to behavioral events. Nature 373:515-518. 